\title{
Active Earth Pressure Against Flexible Retaining Wall For Finite Soils Under The Drum Deformation Mode
}

\section{Hu Weidong}

Hunan Institute of Science and Technology

Zhu Xinnian (D11999496@hnist.edu.cn)

Hunan Institute of Science and Technology

Zeng Yongqing

Hunan Institute of Science and Technology

Xiaohong Liu

Hunan Institute of Science and Technology

Peng Chucai

Hunan Institute of Science and Technology

\section{Research Article}

Keywords: active earth pressure, non-limit state, soil arch, differential level layer method, drum deformation mode, flexible retaining wall

Posted Date: September 8th, 2021

DOI: https://doi.org/10.21203/rs.3.rs-877838/v1

License: (c) (1) This work is licensed under a Creative Commons Attribution 4.0 International License. Read Full License 
1 Active earth pressure against flexible retaining wall for finite soils under the drum deformation mode

\footnotetext{
${ }^{1}$ Professor, College of Civil Engineering and Architecture, Hunan Institute of Science and Technology, Yueyang
} 414000, China. Email: 11996498@hnist.edu.cn

${ }^{2}$ Lecturer, College of Civil Engineering and Architecture, Hunan Institute of Science and Technology, Yueyang 414000, China(Corresponding author). Email: 11999496@hnist.edu.cn

${ }^{3}$ Ph.D. College of Civil Engineering and Architecture, Hunan Institute of Science and Technology, Yueyang 414000, China. Email: yqzeng@hnist.edu.cn

${ }^{4}$ Professor, College of Civil Engineering and Architecture, Hunan Institute of Science and Technology, Yueyang 414000, China. Email: 11991491@ hnist.edu.cn

${ }^{5} \mathrm{Ph} . \mathrm{D}$. College of Civil Engineering and Architecture, Hunan Institute of Science and Technology, Yueyang 414000, China. Email:12017016@hnist.edu.cn

Corresponding author: Zhu Xinnian*, Lecturer, Email: 11999496@hnist.edu.cn

Abstract: A reasonable method is proposed to calculate the active earth pressure of finite soils based on the drum deformation mode of the flexible retaining wall close to the basement's outer wall. The flexible retaining wall with cohesionless sand is studied, and the ultimate failure angle of finite soils close to the basement's outer wall is obtained using the Coulomb theory. Soil arch theory is led to get the earth pressure coefficient in the subarea using the trace line of minor principal stress of circular arc after stress deflection. The soil layers at the top and bottom part of the retaining wall are restrained when the drum deformation occurs, and the soil layers are in a non-limit state. The linear relationship between the wall movement's magnitude and the mobilization of the internal friction angle and the wall friction anger is presented. The level layer analysis method is modified to propose the resultant force of active earth pressure, the action point's height, and the pressure distribution. Model tests are carried out to emulate the process of drum deformation and soil rupture with limited width. Through image analysis, it is found that the failure angle of soil within the limited width is larger than that of infinite soil. With the increase of the aspect ratio, the failure angle gradually reduces and tends to be constant. Compared with the test results, it is showed that the horizontal earth pressure reduces with the reduction of the aspect ratio within critical width, and the resultant force decreases with the increase of the limit state region under the same ratio. The middle part of the distribution curve is concave. The active earth pressure strength decreases less than Coulomb's value, the upper and lower soil layers are in the non-limit state, and the active earth pressure strength is more than 
Coulomb's value.

Key words: active earth pressure; non-limit state; soil arch; differential level layer method; drum deformation mode; flexible retaining wall

\section{Introducion}

Deep foundation pits are often excavated near the basement of existing buildings in urban and municipal engineering. The undisturbed soil between the retaining wall and the existing basement's outer wall is narrow and its width is limited, which is also the research object of this paper. Row pile wall, underground diaphragm wall, and sheet pile wall have been great used in enclosure structure of foundation pit engineering and slope engineering. The thickness of the retaining wall structure is minimal compared with the height. The wall has obvious flexure deformation, which can't meet the rigid retaining wall's assumption, called the flexible retaining wall. The classical earth pressure theories of Coulomb and Rankine cannot accurately predict the earth pressure on the flexible retaining wall.

The structural deformation of the retaining wall caused by the excavation of internal support and anchor pull system can be classified into three types (Clough and O'Rourke 1990; Milligan 1983; Zhang et al.1998). The first type is a cantilevered triangle with the largest displacement at the top of the wall. The second type is drum deformation because the upper part of the flexible retaining wall is supported. The bottom of the wall is embedded in the soil, which shows that the displacement of the top and bottom of the wall is unchanged. The abdomen of the retaining wall structure protrudes into the foundation pit, and the displacement curve is parabolic. The third type of deformation is the combination of the first two. For the supporting and anchoring flexible retaining wall, the drum deformation mode bulging into the pit is the most typical one, which is also the basis of studying other combined modes of wall movement. It is of great significance to study the deformation's behavior, the failure mechanism, and the earth pressure distribution.

The drum deformation mode of the flexible retaining wall is characterized by large deformation in the middle and small deformation at both ends. The horizontal displacement of soil is mostly parabolic. The earth pressure on the retaining wall is nonlinear along with the wall's height, which is affected by the magnitudes of displacement and the displacement mode of wall movement. Milligan (1983) carried out the model test of flexible retaining wall with support at the 
top, studied the relationship between the drum deformation of the wall and the displacement of the soil, and the development of sliding surface behind the wall. Lu et al. (2003) carried out the active earth pressure and displacement tests of a cantilever and single anchor flexible retaining wall, and obtained the R-shaped distribution of active earth pressure along the anchored retaining wall. Zhang et al.(1998) presented the relationship between the coefficient of earth pressure of sand and the increment ratio of axial and lateral strain based on the triaxial test. They deduced the unified expression of displacement and the calculation method of earth pressure under any displacement state. Based on the previous experiments and numerical analysis, the calculation method of active earth pressure resultant force and its distribution on flexible retaining walls under arbitrary displacement is proposed by Ying et al. (2014).

Under the drum deformation mode, the top of the wall is constrained by the support, and the soil layers constrain the bottom of the wall. The deformation feature can be seen as the upper wall rotates outward around the top of the wall, while the lower wall rotates outward around the bottom of the wall (Gong et al. 2005; Matsuzaw 1996; Wang et al.2003; Chang 1997; Fang 1986). There is a relative displacement tendency between the upper and lower soils during the deformation, resulting in the horizontal shearing stress, which cannot be ignored. Therefore, the coefficient and distribution of active earth pressure are affected. The deformation and earth pressure distribution of the soil layer near the top and bottom of the wall has RT mode and RB mode characteristics.

The existing theoretical research is still insufficient. Based on the relationship between the unit earth pressure and the horizontal displacement, the calculation formulas (Zhang et al. 1998; $\mathrm{Xu}$ 2000; Mei et al.2001) were put forward, but the relative displacement was not considered under the drum deformation. The results show that the distribution of earth pressure is always between the static and active states, which can't reflect the redistribution of earth pressure caused by the drum deformation of flexible retaining walls. Ying et al. (2008) considered the relative displacement of the adjacent depth soil layers, but the earth pressure dropped sharply at the wall's maximum displacement, which was unreasonable.

The deformation of the soil layer near the top and bottom of the retaining wall is limited, and it is impossible to reach a limit state in company with the soil layer in the middle abdomen. The rotating angle of the retaining wall is small when in service, which makes the displacement of the soil near the top and bottom of the wall very small, and it is not easy to reach the limit state. The shearing strength of soil and friction between wall and soil can't be fully mobilized, and they are 
actually in a non-limit active state. The magnitude of active earth pressure is affected by the drum deformation mode, which causes the redistribution of earth pressure. The soil layer's active earth pressure near the top and bottom of the wall increases due to the soil arching (Paik and Salgado 2003; Handy 1985; Hu et al. 2020a), while the active earth pressure of the soil layer in the middle of the wall decreases relatively.

Therefore, to better study the active earth pressure against the flexible retaining wall, the wall movement mode, the actual non-limit active state of the soil layer near the top and bottom of the wall, and the soil arching should be taken into account (Lin et al. 2020; Hu et al. 2020a; Zhu and Zhao 2014; Take and Valsangkar 2001; Liu 2018; Naki 1985). The soil behind the flexible retaining wall near the outer wall of the existing basement or the vertical slope is filled with limited width soil (Chen et al. 2019a; Chen et al. 2019b; Xie et al.2019; Hu et al.2020b), which has attracted more and more attention in practical engineering.

The soil arch theory is led into this research based on the progressive rupture mechanism in the cohesionless sand under drum formation mode. The differential level layer unit method is applied to analyze the partition unit. Considering the shearing stress and the partial mobilization of shearing strength and wall friction in a non-limit state, the distribution of the active earth pressure, the resultant force's magnitude, and the action point's height are obtained. The model tests are conducted to verify further the proposed method in the paper.

\section{Analysis model of flexible retaining wall}

The retaining wall is close to the basement outer wall or vertical rock slope, and the height of the retaining wall is $H$, as shown in Figure 1. Cohesionless sand is filled behind the retaining wall, the narrow width is $l=n \cdot H$ ( $n$ is the ratio of width to height).

The middle abdomen of the flexible retaining wall protrudes into the excavation under the top strut's support and the constraint of the embedded end at the bottom, forming a drum deformation. The only rotation occurs at the top and bottom of the retaining wall, and its horizontal displacement is assumed to be zero. It is assumed that the midpoint $H / 2$ is the place of maximum deformation and horizontal displacement. Because of the limited width of retaining sand, the slip plane is cut off by the outer wall or rock slope and cannot fully develop to the sand top surface. Thus, the height of the wall is divided into $H_{1}$ and $H_{2}$. The sliding surface is assumed to be a plane, passing through the bottom of the wall and forming an angle $\beta$ with the level plane.

Due to the different widths of the limited soil, the intersection point $c$ of slip surface and 
vertical external wall or rock slope may be higher or lower than the maximum horizontal

126 displacement of the midpoint, including two cases, as shown in Figure 1. When $H_{1} \leq H / 2$, the soil 127 mass is divided into upper and lower areas with ce as the boundary. The area above the ce 128 boundary is the zone I, and the area below the ce boundary is divided into zones II, III, and IV 129 from top to bottom. The up thin layer at the maximum horizontal displacement is the intermediate 130 transition zone III (Figure 1 (a)). When the width is minimal, $H_{1}>H / 2$, the area below the $c e$ 131 boundary in zone IV, and the area above the $c e$ boundary is divided into zones I, II, and III from 132 top to bottom. The up thin layer at the maximum horizontal displacement is the intermediate transition zone II (Figure 1 (b)).

134

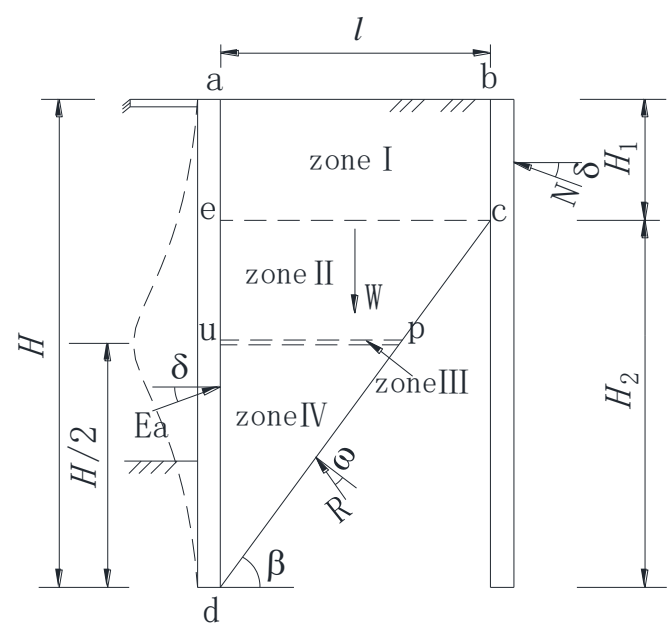

(a) $H_{1} \leq H / 2$

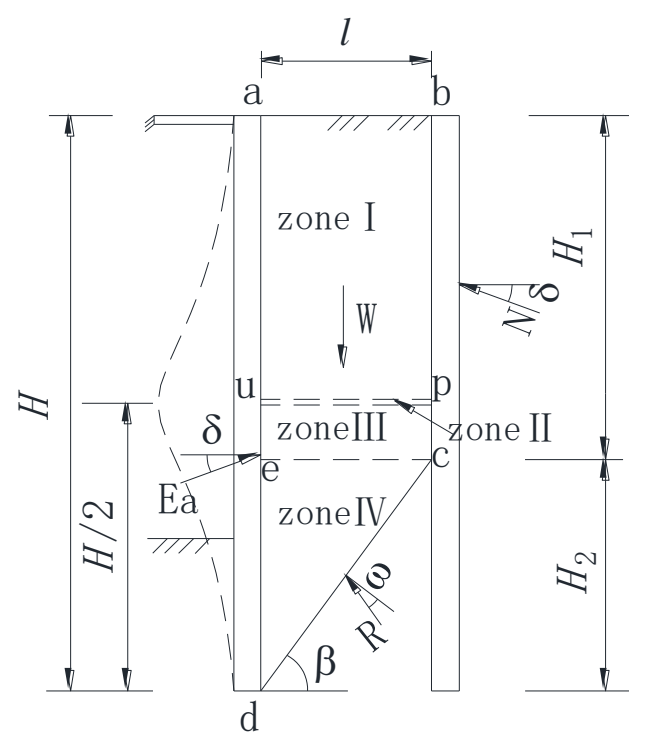

(b) $H_{1}>H / 2$

Fig.1 Slip surface 

approximately considered that the earth pressure distribution on the wall meets the triangular

141 distribution along with the height. Therefore, it is the same at the same depth (Jie 2019; Wang et al.

142 2014a; Hu et al.2020a). By introducing the parameter $m$, then:

$$
N=m E_{a}=\left(\frac{H_{1}}{H}\right)^{2} E_{a}
$$

$E_{a}$ is the resultant force of active earth pressure acting below the normal, and its direction is $\delta$ angle from the normal of the back of the wall.

Based on the Coulomb method, the vertical and horizontal equilibrium function of soil on the sliding surface is derived.

$$
E_{a}=\frac{\frac{1}{2} \gamma n H^{2}(2-n \tan \beta)}{\sin \delta\left[1+(1-n \tan \beta)^{2}\right]+\cos \delta \cot (\beta-\varphi)\left[1-(1-n \tan \beta)^{2}\right]}
$$
dangerous sliding surface as the soil enters an active limit state. The value of the extreme thrust $E_{a}$ can be obtained by using Eq.(2) (Hu et al.2020a).

\section{The active earth pressure coefficient}

Firstly, taking the situation shown in Fig. 1 (a) as the research object, the earth pressure coefficient and the soil arching are analyzed. $c e$ is taken as the boundary line according to the different boundary conditions of the finite soil.

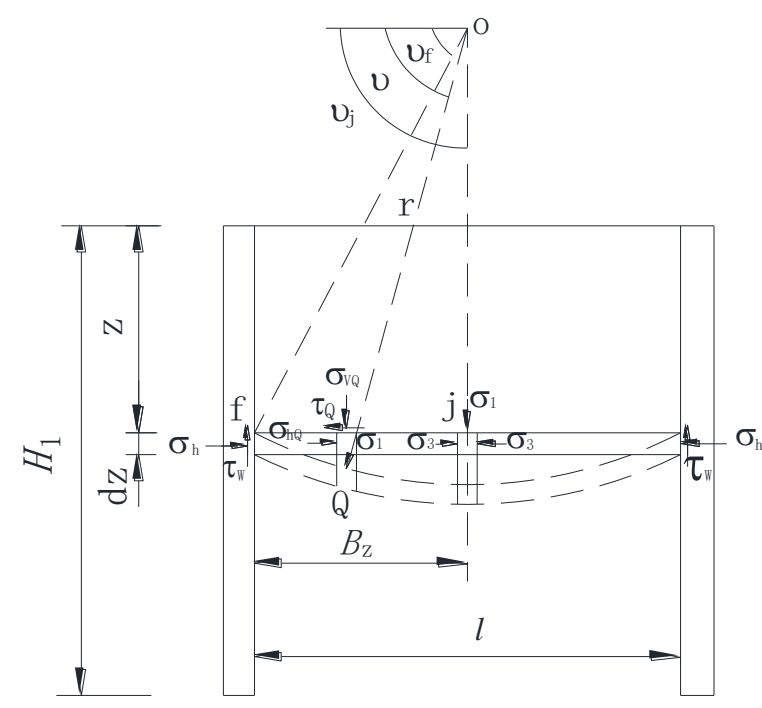



process of drum deformation and ground subsidence, because of friction between two vertical parallel walls, the stress deflection occurs due to the soil arch, and the horizontal stress on the retaining wall is no longer minor principal stress. The horizontal layer unit at depth $z$ (in zone I) is taken for analysis. The minor principal stress trajectories of each point are connected to form a continuous arch curve, as shown in Fig. 2. Although the stress and boundary conditions of the retaining soil in the lower zones II, III, and IV are different from those in the upper zone I, the vertical and lateral deformation are also limited by frictions (the interface friction between the retaining wall and the retaining soil and the soil friction on the failure plane). Therefore, the direction of the principal stress deflects, and its magnitude remains unchanged along the arch. Taking the layer unit at depth $z$ (in zones II, III and IV) for analysis shown in Fig. 3, each point's minor principal stress trajectories on the horizontal unit forms a half arch. Moreover, the horizontal shearing stress exists on the level unit's surface objectively, and the shearing stress of each point is not equal because of the unequal deflection angle of each point.

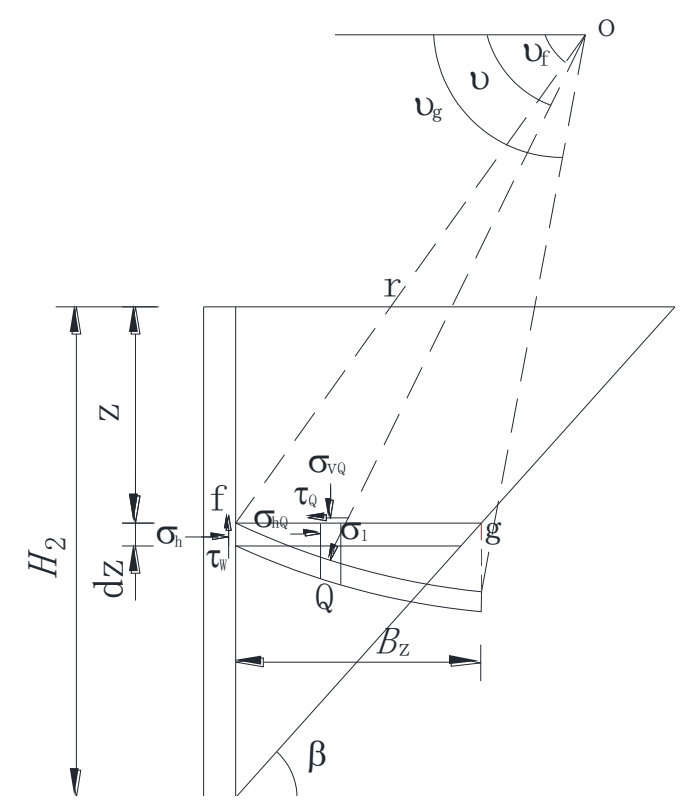

Fig.3 Trajectory of minor principal stress in zone II,III,IV

The circular arch is employed generally for analysis by many scholars (Wang 2014b; Hu et al.2020a; Lin et al. 2020; Cao et al.2019). Since the circular arch's calculation results are close to those of other shapes of arch curves, the circular arch stress trajectory is used to establish the calculation model in this paper. 

the circle is point $O$. The vertical stress distribution on the layer unit at depth $z$ is uneven considering the soil arching effect. Herein, according to the study by Handy (1985) and Paik and Salgado (2003), the lateral active earth pressure coefficient $K_{\text {awn }}$ is defined as

$$
K_{a w n}=\frac{\sigma_{h}}{\overline{\sigma_{v}}}
$$

Where $\sigma_{h}$ is the normal earth pressure on the interface between retaining wall and soil at the depth $z, \overline{\sigma_{v}}$ is the average erect pressure on the level at the same height.

The stress of point $Q$ on the arch line is expressed as follows.

$$
\left.\begin{array}{l}
\sigma_{v Q}=\frac{\sigma_{1}}{1+\sin \varphi}(1-\sin \varphi \cos 2 \theta) \\
\sigma_{h Q}=\frac{\sigma_{1}}{1+\sin \varphi}(1+\sin \varphi \cos 2 \theta) \\
\tau_{Q}=\frac{\sigma_{1} \sin \varphi}{1+\sin \varphi} \sin 2 \theta
\end{array}\right\}
$$

Where $\sigma_{1}$ is the major principal stress and $\theta$ is the deflection angle between the major principal stress and the level at point $Q$. The deflection angles at point $f$ and $g$ are indicated as:

$$
\left.\begin{array}{l}
\theta_{f}=\left[\pi-\arcsin \left(\frac{\sin \delta}{\sin \varphi}\right)+\delta\right] / 2 \\
\theta_{g}=\pi / 4-\varphi / 2+\beta
\end{array}\right\}
$$

Considering the symmetry of soil mass in zone I, half of the circular arch trajectory can be taken for analysis. The horizontal $\operatorname{span} B_{\mathrm{z}}$ is $l / 2$, the deflection angle at point $j$ is $\theta_{j}=\pi / 2$, and the average vertical stress along the arch in zone I is

$$
\overline{\sigma_{v}}=\int_{\theta_{f}}^{\theta_{j}} \frac{\sigma_{v Q} r \sin \theta d \theta}{B_{z}}=\sigma_{1}-\frac{2 \sin \varphi \cos ^{2} \theta_{f}}{3(1+\sin \varphi)} \sigma_{1}
$$

In the formula, the curve radius of the minor principal stress arch curve is $r$ $=B_{z} /\left(\cos \theta_{f}-\cos \theta_{j}\right)$. The lateral coefficient of active earth pressure $K_{a w n 1}$ in zone I can be presented from Eq. (4) and Eq. (6),

$$
K_{a w n 1}=\frac{\sigma_{h}}{\overline{\sigma_{v}}}=\frac{3\left(1+\sin \varphi \cos 2 \theta_{f}\right)}{3(1+\sin \varphi)-2 \sin \varphi \cos ^{2} \theta_{f}}
$$




$$
\bar{\tau}=\int_{\theta_{f}}^{\theta_{j}} \frac{\tau_{Q} r \sin \theta d \theta}{B_{z}}=\frac{2 \sin \varphi\left(1-\sin ^{3} \theta_{f}\right)}{3(1+\sin \varphi) \cos \theta_{f}} \sigma_{1}
$$

200

The average shearing stress coefficient $k$ is defined as average shearing stress ratio to average vertical stress on the level layer unit, which should be less than $\tan \varphi$.

$$
k=\frac{\bar{\tau}}{\overline{\sigma_{v}}}
$$

Thus, the average shearing stress coefficient $k_{1}$ of soil in zone I can be given

$$
k_{1}=\frac{\bar{\tau}}{\overline{\sigma_{v}}}=\frac{2 \sin \varphi\left(1-\sin ^{3} \theta_{f}\right)}{3(1+\sin \varphi) \cos \theta_{f}-2 \sin \varphi \cos ^{3} \theta_{f}}
$$

To the lower soil in zones II, III and IV, the average vertical stress on the track line of minor principal stress arching can be expressed as

$$
\overline{\sigma_{v}}=\int_{\theta_{f}}^{\theta_{g}} \frac{\sigma_{v Q} r \sin \theta d \theta}{B_{z}}=\sigma_{1}-\frac{2 \sin \varphi\left(\cos ^{3} \theta_{f}-\cos ^{3} \theta_{g}\right)}{3(1+\sin \varphi)\left(\cos \theta_{f}-\cos \theta_{g}\right)} \sigma_{1}
$$

Where, the radius $r=B_{z} /\left(\cos \theta_{f}-\cos \theta_{g}\right)$. Similarly, the lateral coefficient of active earth pressure $K_{a w n 2}=K_{a w n 3}=K_{a w n}$ and the coefficient of average shearing stress $k_{2}=k_{3}=k_{4}$ can be obtained in zones II, III and IV

$$
\begin{gathered}
K_{a w n 2}=\frac{\sigma_{h}}{\overline{\sigma_{v}}}=\frac{3\left(1+\sin \varphi \cos 2 \theta_{f}\right)}{3(1+\sin \varphi)-2 \sin \varphi\left(\cos ^{2} \theta_{f}+\cos ^{2} \theta_{g}+\cos \theta_{f} \cos \theta_{g}\right)} \\
k_{2}=\frac{\bar{\tau}}{\overline{\sigma_{v}}}=\frac{2 \sin \varphi\left(\sin ^{3} \theta_{g}-\sin ^{3} \theta_{f}\right)}{3(1+\sin \varphi)\left(\cos \theta_{f}-\cos \theta_{g}\right)-2 \sin \varphi\left(\cos ^{3} \theta_{f}-\cos ^{3} \theta_{g}\right)}
\end{gathered}
$$

Suppose the ultimate rupture angle is $\beta=\pi / 4+\varphi / 2, K_{a w n 1}=K_{a w n}, k_{1}=k_{2}$. If $\beta=\pi / 4+\varphi / 2$ and $\delta=0$, Eqs. (7) and (12) is able to transform into $K_{a w n 1,2}=\tan ^{2}(\pi / 4-\varphi / 2)$, that is Rankine coefficient.

Furthermore, taking the situation shown in Fig. 1 (b) as the research object, the coefficient of earth pressure and soil arching are analyzed according to the same method above. Then, we can get the lateral active earth pressure coefficients $K_{a w n 1}, K_{a w n 2}, K_{a w n 3}$, and average shearing stress coefficients $k_{1}, k_{2}, k_{3}$ in zones I, II, and III.

$$
K_{a w n 1}=K_{a w n 2}=K_{a w n 3}=\frac{3\left(1+\sin \varphi \cos 2 \theta_{f}\right)}{3(1+\sin \varphi)-2 \sin \varphi \cos ^{2} \theta_{f}}
$$




$$
k_{1}=k_{2}=k_{3}=\frac{2 \sin \varphi\left(1-\sin ^{3} \theta_{f}\right)}{3(1+\sin \varphi) \cos \theta_{f}-2 \sin \varphi \cos ^{3} \theta_{f}}
$$

221

The coefficient of lateral active earth pressure $K_{a w n}$ and average shearing stress $k_{4}$ in zone IV are obtained.

$$
\begin{gathered}
K_{a w n 4}=\frac{3\left(1+\sin \varphi \cos 2 \theta_{f}\right)}{3(1+\sin \varphi)-2 \sin \varphi\left(\cos ^{2} \theta_{f}+\cos ^{2} \theta_{g}+\cos \theta_{f} \cos \theta_{g}\right)} \\
k_{4}=\frac{2 \sin \varphi\left(\sin ^{3} \theta_{g}-\sin ^{3} \theta_{f}\right)}{3(1+\sin \varphi)\left(\cos \theta_{f}-\cos \theta_{g}\right)-2 \sin \varphi\left(\cos ^{3} \theta_{f}-\cos ^{3} \theta_{g}\right)}
\end{gathered}
$$

\section{Parameter value in non-limit state}

The horizontal displacement of the retaining wall is $s$ under the drum movement mode, and the magnitude of displacement at the middle point is the largest, which value is $s_{\max }$. Assuming that the horizontal displacement required for the soil to enter the full limit state is $s_{\mathrm{a}}$, the area with the displacement $s \geqslant_{\mathrm{a}}$ is the full limit state area, where the internal friction angle of the fill and the external wall friction angle are fully mobilized. In this paper, the region is defined as the intermediate transition region.

The area with horizontal displacement $s<s_{\mathrm{a}}$ of retaining wall is a non-limit state area. In the non-limit state, because of the small magnitude of displacement, the soil friction angle $\varphi^{\prime}$ and the wall friction angle $\delta^{\prime}$ partial mobilize that their values are between the initial state values $\varphi_{0}, \delta_{0}$, and the ultimate state values $\varphi, \delta$, respectively. Considering that the mobilization of $\varphi^{\prime}$ and $\delta^{\prime}$ are affected by the magnitude of horizontal displacement of the retaining wall, it is assumed that $\varphi^{\prime}$ and $\delta^{\prime}$ increase linearly with the increase of horizontal displacement, the following expression is given by

$$
\left.\begin{array}{l}
0 \leq z \leq \frac{H}{2}-\frac{\Delta z}{2}, \varphi^{\prime}=\tan ^{-1}\left[\tan \varphi_{0}+\frac{z}{H / 2-\Delta z / 2}\left(\tan \varphi-\tan \varphi_{0}\right)\right] \\
\frac{H}{2}-\frac{\Delta z}{2} \leq z \leq \frac{H}{2}+\frac{\Delta z}{2}, \varphi^{\prime}=\varphi \\
\frac{H}{2}+\frac{\Delta z}{2} \leq z \leq H, \varphi^{\prime}=\tan ^{-1}\left[\tan \varphi_{0}+\frac{H-z}{H / 2-\Delta z / 2}\left(\tan \varphi-\tan \varphi_{0}\right)\right]
\end{array}\right\}
$$




$$
\left.0 \leq z \leq \frac{H}{2}-\frac{\Delta z}{2}, \delta^{\prime}=\tan ^{-1}\left[\tan \delta_{0}+\frac{z}{H / 2-\Delta z / 2}\left(\tan \delta-\tan \delta_{0}\right)\right]\right)
$$

$$
\varphi_{0}=\sin ^{-1}\left[\frac{1-K_{0}}{1+K_{0}}\right]
$$

In which,

$$
K_{0}=1-\sin \varphi
$$

In general, $\delta=2 \varphi / 3$ and $\delta_{0}=\varphi / 2$. The variation of $\varphi^{\prime}$ and $\delta^{\prime}$ along the retaining wall under drum deformation mode is shown in Figure 4.

248

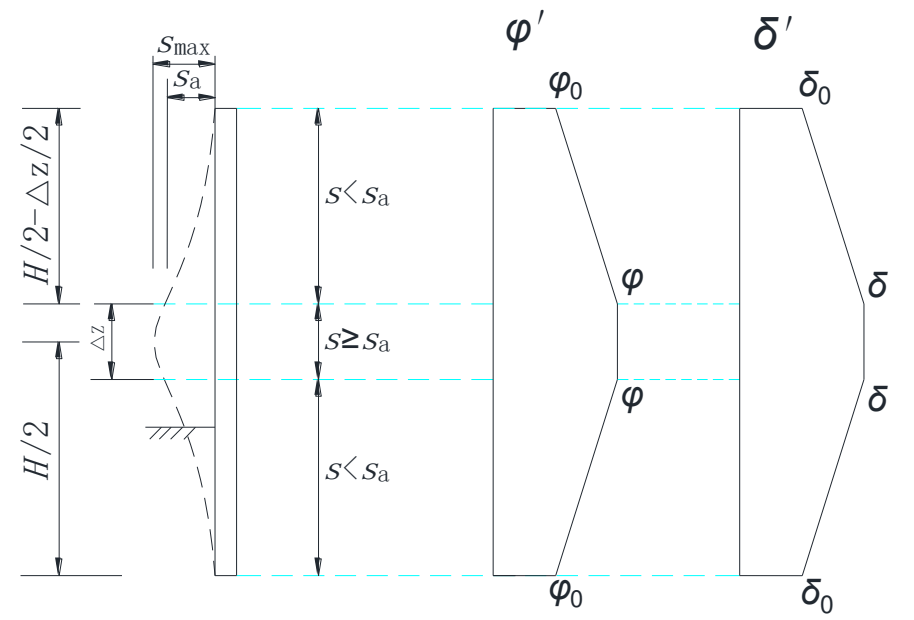

Fig.4 $\varphi^{\prime}$ and $\delta^{\prime}$ along the height of retaining wall

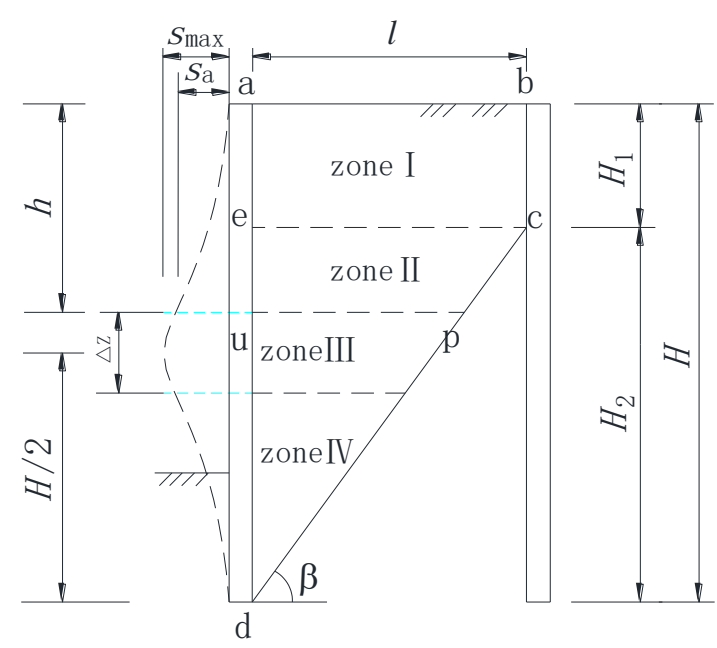

(a) $H_{1} \leq H / 2$ 


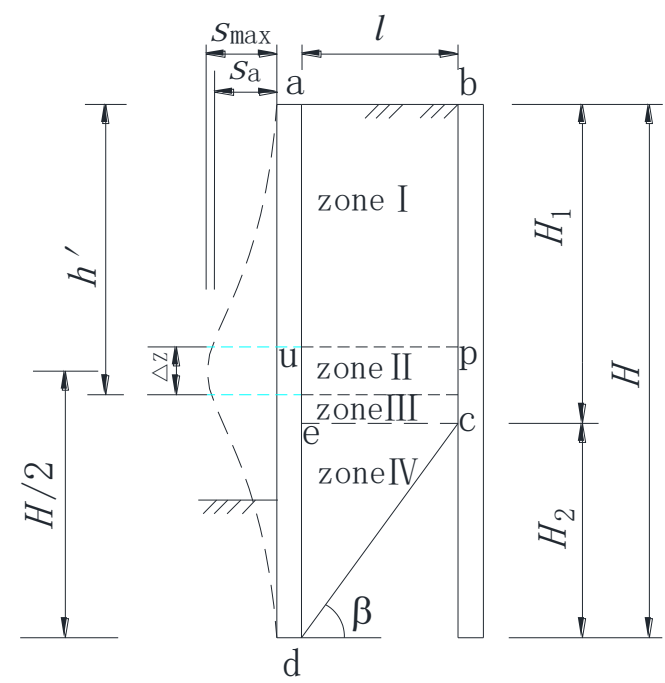

(b) $H_{1}>H / 2$

Fig.5 Drum deformation displacement mode of flexible retaining wall

The height of the intermediate transition zone is set as $\Delta z=x \cdot H$, the soil mass within the height $\Delta z$ reaches the active limit equilibrium state. $\mathrm{x}$ is the ratio of soil layer height entering the limit state along the retaining wall. For the first case of $H_{1} \leq H / 2$, as shown in Fig. 5 (a), the depth from the top surface of the transition zone to the fill's top surface is $h=H / 2-\Delta z / 2$. In this paper, the depth $h$ is limited to $\left[H_{1}, H / 2\right]$, where $h$ tends to $H_{1}$ with $\Delta z$ increases. When $\Delta z / 2 \geqslant H / 2-H_{1}$, the original zone II disappears, and the depth of the top surface of the transition zone is calculated as $h=H_{1}$. When $\Delta z \rightarrow 0, h$ tends to $H / 2$ and is calculated as $h=H / 2$, which is the thin transition layer shown in Fig. 1 (a).

For the second case of $H_{1}>H / 2$, as shown in Figure 5 (b), the height from the bottom of the transition zone to the top of the fill is set as $h^{\prime}=H / 2+\Delta z / 2$. In this paper, the depth $h^{\prime}$ is limited to [H/2, $\left.H_{1}\right]$, where $h^{\prime}$ tends to $H_{1}$ with $\Delta \mathrm{z}$ increases. When $\Delta z / 2 \geqslant H_{1}-H / 2$, the original area III disappears, and the depth of the bottom surface of the transition zone is calculated as $h^{\prime}=H_{1}$. When $\Delta z \rightarrow 0, h^{\prime}$ tends to $H / 2$ and is calculated as $h^{\prime}=H / 2$, which is the thin transition layer shown in Figure $1(b)$.

\section{Solution for active earth pressure strength}

The shearing stress on the level unit surface is normally not considered under the translation mode ( $\mathrm{T}$ ) because the soil mass moves as a whole, and there is no relative movement between the horizontal soil layers. However, under the drum movement mode, the flexible retaining wall can 
be regarded as the upper retaining wall rotating about the top of the wall (RT) and the lower retaining wall rotating about the bottom of the wall (RB). Each soil layer produces relative motion in the rotation direction with respect to the below layer. There must be level shearing stress between the upper and lower soil. The distribution of shearing stress is very complex, and it will affect the moment balance condition. If the moment equilibrium condition is not involved in the derivation, then the specific distribution of shear stress is not concerned (Liu et al.2016, 2018). Nevertheless, different stress distribution assumptions on the horizontal plane will not affect two static equilibrium of force along with the horizontal and vertical directions.

In this paper, the differential level layer method is introduced. According to the relative movement trend of the horizontal layer unit of the soil wedge behind the wall, the action direction of the friction shearing stress between the level layer units in each zone is determined (Chen et al. 2009; Hu et al.2020a 2020b; Liu et al. 2016). Under the condition of satisfying the balance of forces, the active earth pressure differential equation in a non-limit state is established, and then its distribution is discussed.

\section{Zone I}

The level layer unit in zone I is shown in Figure 6, and the static equilibrium equations are established.

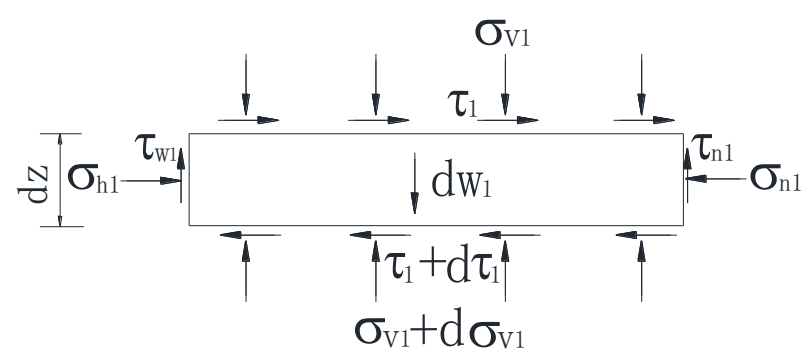

Fig.6 Forces acting on level units in zone I

$$
\begin{gathered}
\sigma_{h 1} d z-\sigma_{n 1} d z-n H d \tau_{1}=0 \\
\tau_{w 1} d z+n H d \sigma_{v 1}+\tau_{n 1} d z-d w_{1}=0
\end{gathered}
$$

In which, the second order differentiation has been omitted, $\sigma_{\mathrm{v} 1}$ is the vertical stress on the layer unit at depth $z$, and $\sigma_{\mathrm{h} 1}$ is the lateral active earth pressure.

$$
\sigma_{h 1}=K_{a w n 1} \sigma_{v 1}
$$

$\tau_{1}$ is the horizontal shearing stress on the surface of the layer unit, assuming it is average 
distribution, it can be obtained.

$$
\tau_{1}=k_{1} \sigma_{v 1}
$$

Where $\tau_{\mathrm{w} 1}$ is the shearing stress on the interface, and the magnitude of $\tau_{\mathrm{w} 1}$ is:

$$
\tau_{w 1}=\sigma_{h 1} \tan \delta^{\prime}
$$

$\sigma_{\mathrm{n} 1}$ is the horizontal lateral pressure on the outer wall at depth $z$, and $\tau_{\mathrm{n} 1}$ is the shearing stress. $\tau_{\mathrm{n} 1}$ can be expressed by

$$
\tau_{n 1}=\sigma_{n 1} \tan \delta^{\prime}
$$

$d w_{1}$ is the self-weight of the level unit in zone I, and its magnitude is obtained as:

$$
d w_{1}=\gamma n H d z
$$

In general, there are

$$
\left(1-k_{1} \tan \delta^{\prime}\right) \frac{d \sigma_{v 1}}{d z}+\frac{2 K_{a w n 1} \tan \delta^{\prime}}{n H} \sigma_{v 1}-\gamma=0
$$

When $z=0, \sigma_{\mathrm{v} 1}=0$ is regarded as the boundary condition of zone I, the first-order linear differential equation (Eq.29) can be solved as follows.

$$
\sigma_{v 1}=\frac{\gamma}{B}-\frac{\gamma}{B} e^{\left(-\frac{B}{A} z\right)}
$$

312 In which

$$
\left.\begin{array}{l}
A=1-k_{1} \tan \delta^{\prime} \\
B=\frac{2 K_{a w n 1} \tan \delta^{\prime}}{n H}
\end{array}\right\}
$$

314 When $z=H_{1}, \sigma_{\mathrm{v} 1}=D_{1}$ can be regarded as the boundary condition of equivalent load on the surface of 315 the isolated body in zone II.

$$
D_{1}=\frac{\gamma}{B}-\frac{\gamma}{B} e^{\left(-\frac{B}{A} H_{1}\right)}
$$

\section{Zone II}

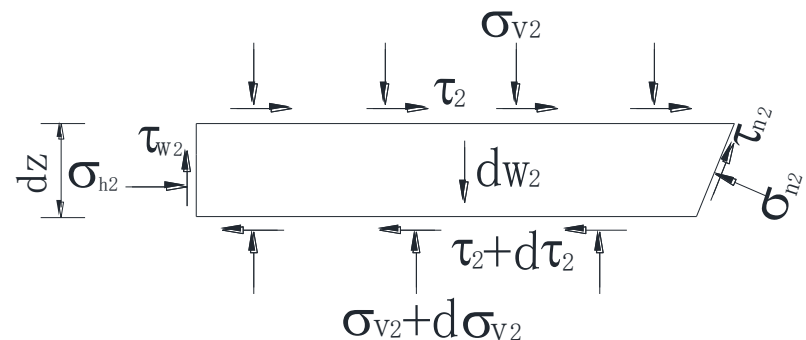



on the layer unit (Figure 7), the equation is established. The second-order differential components are omitted to obtain.

$$
\begin{gathered}
\sigma_{h 2} d z+\tau_{2} d z \cot \beta-d \tau_{2}(H-z) \cot \beta-\sigma_{n 2} d z+\tau_{n 2} \cot \beta d z=0 \\
\tau_{w 2} d z-\cot \beta \sigma_{v 2} d z+(H-z) \cot \beta d \sigma_{v 2}+\cot \beta \sigma_{n 2} d z+\tau_{n 2} d z-d w_{2}=0
\end{gathered}
$$

340 in which,

Where $\sigma_{\mathrm{v} 2}$ is the mean vertical normal stress on the surface of layer unit, and $\sigma_{\mathrm{h} 2}$ is the lateral active earth pressure.

$$
\sigma_{h 2}=K_{a w n 2} \sigma_{v 2}
$$

$\tau_{2}$ is the level shearing stress on the soil layer unit. It is assumed to be uniformly distributed, and its magnitude is expressed as follows:

$$
\tau_{2}=k_{2} \sigma_{v 2}
$$

Where $\tau_{\mathrm{w} 2}$ refers to the shearing stress on the interface and its expression is

$$
\tau_{w 2}=\sigma_{h 2} \tan \delta^{\prime}
$$

$\sigma_{\mathrm{n} 2}$ is the normal stress distributed uniformly on the rupture surface. $\tau_{\mathrm{n} 2}$ is the shearing stress distributed uniformly, the formula is

$$
\tau_{n 2}=\sigma_{n 2} \tan \varphi^{\prime}
$$

In which $d w_{2}$ is the self-weight of level layer element in zone II, and its expression is

$$
d w_{2}=\gamma(H-z) \cot \beta d z
$$

By synthesizing the above formula, the first order differential equation is obtained,

$$
F \frac{d \sigma_{v 2}}{d z}+G \frac{\sigma_{v 2}}{(H-z)}-\gamma=0
$$

Eq. (40) and Eq. (32) are solved to present the following equation.

$$
\left.\begin{array}{l}
F=\left(1+k_{2} C\right) \\
G=\tan \beta\left[K_{a w n 2} \tan \delta^{\prime}-\cot \beta-C\left(k_{2} \cot \beta+K_{a w n 2}\right)\right] \\
C=\frac{\cot \beta+\tan \varphi^{\prime}}{\cot \beta \tan \varphi^{\prime}-1}
\end{array}\right\}
$$




$$
\sigma_{v 2}=\frac{-\gamma(H-z)}{F-G}+\left[D_{1}+\frac{\gamma\left(H-H_{1}\right)}{F-G}\right]\left(\frac{H-z}{H-H_{1}}\right)^{\frac{G}{F}}
$$

344

By substituting Eq. (42) into Eq. (35), the horizontal active earth pressure in zone II is derived.

When $z=h, \sigma_{\mathrm{v} 2}=D_{2}$ is regarded as the boundary condition of equivalent load on zone III.

$$
D_{2}=\frac{-\gamma(H-h)}{F-G}+\left[D_{1}+\frac{\gamma\left(H-H_{1}\right)}{F-G}\right]\left(\frac{H-h}{H-H_{1}}\right)^{\frac{G}{F}}
$$

\section{Zone III}

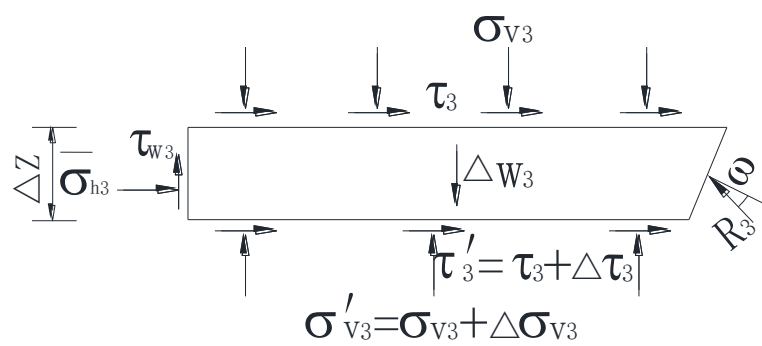

Fig.8 Forces acting on level units in zone III

Zone III is the middle transition layer, in which the shearing strength of the soil is fully mobilized, the internal friction angle of fill is $\varphi^{\prime}=\varphi$, and the external friction angle between walls and soils is $\delta^{\prime}=\delta$. The mean vertical compressive stress on the top of layer $(z=h)$ is $\sigma_{\mathrm{v} 3}=D_{2}$, and the mean vertical compressive stress at the bottom of the layer is $\sigma_{\mathrm{v} 3}^{\prime}=\sigma_{\mathrm{v} 3}+\Delta \sigma_{\mathrm{v} 3}$, as shown in Figure 8. When $\Delta z$ is large, the whole isolator in zone III is taken as the research object, and the horizontal and vertical static balance equations are established as follows:

$$
\bar{\sigma}_{h 3}\left(\frac{\Delta z}{2}+\frac{H}{2}-h\right)+k_{3} \sigma_{v 3}(H-h) \cot \beta+k_{3} \sigma_{v 3}^{\prime}\left(\frac{H}{2}-\frac{\Delta z}{2}\right) \cot \beta-R_{3} \sin (\beta-\varphi)=0
$$

and

$$
\bar{\sigma}_{h 3} \tan \delta\left(\frac{\Delta z}{2}+\frac{H}{2}-h\right)-\sigma_{v 3}(H-h) \cot \beta+\sigma_{v 3}^{\prime}\left(\frac{H}{2}-\frac{\Delta z}{2}\right) \cot \beta-\Delta w_{3}+R_{3} \cos (\beta-\varphi)=0
$$

in which, $\bar{\sigma}_{h 3}$ is the mean lateral horizontal stress.

$$
\bar{\sigma}_{h 3}=k_{a v n 3}\left(\frac{\sigma_{v 3}+\sigma_{v 3}^{\prime}}{2}\right)
$$

Thus,

$$
Q \sigma_{v 3}+S \sigma_{v 3}^{\prime}-T=0
$$

in which, 


$$
Q=(H-h) \cot \beta\left[k_{3} \cos (\beta-\varphi)-\sin (\beta-\varphi)\right]+\frac{1}{2} k_{a w n 3}\left(\frac{H}{2}+\frac{\Delta z}{2}-h\right)[\cos (\beta-\varphi)+\tan \delta \sin (\beta-\varphi)]
$$

$$
\left.\begin{array}{l}
S=\left(\frac{H}{2}-\frac{\Delta z}{2}\right) \cot \beta\left[k_{3} \cos (\beta-\varphi)+\sin (\beta-\varphi)\right]+\frac{1}{2} k_{a w n 3}\left(\frac{H}{2}+\frac{\Delta z}{2}-h\right)[\cos (\beta-\varphi)+\tan \delta \sin (\beta-\varphi)] \\
T=\frac{1}{2} \gamma \cot \beta \sin (\beta-\varphi)\left(\frac{3 H}{2}-h-\frac{\Delta z}{2}\right)\left(\frac{H}{2}+\frac{\Delta z}{2}-h\right)
\end{array}\right\}
$$

When $z=h, \sigma_{\mathrm{v} 3}=D_{2}$ is substituted into equation (47) as a known loading condition, $\sigma^{\prime} \mathrm{v} 3$ at the bottom of the layer can be obtained. Assuming $\sigma_{\mathrm{v} 3}^{\prime}=D_{3}$, it can also be regarded as the equivalent load on the insulator's top surface in zone IV. The distribution of $\sigma_{\mathrm{h} 3}$ along the height $\Delta z$ of the middle transition zone can be approximately considered as a linear distribution, and its expression is accordance with its equilibrium conditions, the solution can be obtained.

$$
\sigma_{h 3}=k_{a w n 3}\left[D_{2}+\left(D_{2}-D_{3}\right) \frac{h-z}{(H / 2+\Delta z / 2-h)}\right]
$$

The mean vertical stress at the bottom of the thin transition level unit is

$$
\Delta \sigma_{\mathrm{v} 3}=\frac{-2 k_{3} \sigma_{\mathrm{v} 3}}{k_{3}+\tan (\beta-\varphi)}
$$

$$
\left.\sigma_{\mathrm{v} 3}^{\prime}\right|_{z=h}=\sigma_{\mathrm{v} 3}+\Delta \sigma_{\mathrm{v} 3}=\frac{-k_{3}+\tan (\beta-\varphi)}{k_{3}+\tan (\beta-\varphi)} \sigma_{\mathrm{v} 3}
$$

Therefore, when $\Delta z \rightarrow 0$, the mean pressure stress at the bottom of the thin transition layer is taken as the equivalent load on the insulator's top surface in zone IV, and the formula is as follows.

$$
\left.D_{3}\right|_{z=h}=\frac{-k_{3}+\tan (\beta-\varphi)}{k_{3}+\tan (\beta-\varphi)} D_{2}
$$

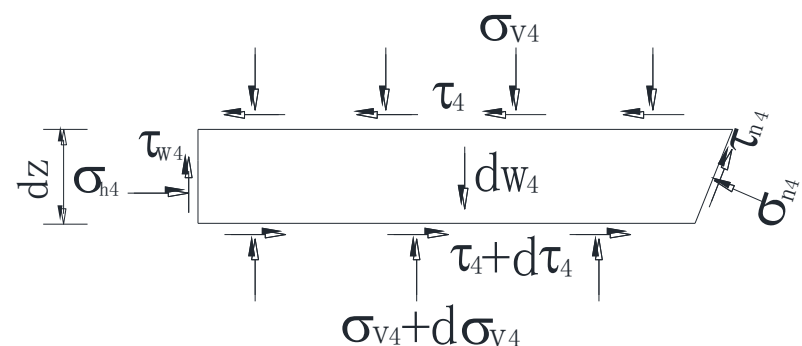


Figure 9), we can get:

$$
\begin{array}{r}
\sigma_{h 4} d z-\tau_{4} d z \cot \beta+d \tau_{4}(H-z) \cot \beta-\sigma_{n 4} d z+\tau_{n 4} \cot \beta d z=0 \\
\tau_{w 4} d z-\sigma_{v 4} d z \cot \beta+(H-z) \cot \beta d \sigma_{v 4}+\sigma_{n 4} d z \cot \beta+\tau_{n 4} d z-d w_{4}=0
\end{array}
$$

In which, $\sigma_{\mathrm{v} 4}$ is the mean direct stress on the layer unit's surface at depth $z$, and $\sigma_{\mathrm{h} 4}$ is the

horizontal active earth pressure.

$$
\sigma_{h 4}=K_{a w n 4} \sigma_{v 4}
$$

$\tau_{4}$ is the level shearing stress on the surface of the layer unit, assuming a mean distribution, and its expression is:

$$
\tau_{4}=k_{4} \sigma_{v 4}
$$

Where $\tau_{\mathrm{w} 4}$ is the shearing stress on the contact surface, and its expression is:

$$
\tau_{w 4}=\sigma_{h 4} \tan \delta^{\prime}
$$

$\sigma_{\mathrm{n} 4}$ is the normal stress and $\tau_{\mathrm{n} 4}$ is the friction shearing stress, which is expressed as:

$$
\tau_{n 4}=\sigma_{n 4} \tan \varphi^{\prime}
$$

In which, $d w_{4}$ is the self-weight of level layer unit in zone IV, which can be expressed as:

$$
d w_{4}=\gamma(H-z) \cot \beta d z
$$

400

401

402

403

By synthesizing the above formula, the first order differential equation can be get,

$$
J \frac{d \sigma_{v 4}}{d z}+L \frac{\sigma_{v 4}}{(H-z)}-\gamma=0
$$

in which,

By using the boundary condition, i.e. the mean vertical stress $\sigma_{\mathrm{v} 4}=D_{3}$ on the top of zone IV, we 405

$$
\text { can solve the differential equation (60) and get }
$$

$$
\sigma_{v 4}=\frac{-\gamma(H-z)}{J-L}+\left[D_{3}+\frac{\gamma(H / 2-\Delta z / 2)}{J-L}\right]\left(\frac{H-z}{H / 2-\Delta z / 2}\right)^{\frac{L}{J}}
$$


By substituting the above equation (62) with equation (55), the lateral active earth pressure in zone IV is generated.

For calculating the second case of $H_{1}>H / 2$, the same method can be used for analysis. Given the length of the paper, a detailed derivation is omitted. When $z=0, \sigma_{\mathrm{v} 1}=0$ is the boundary condition of zone I, and the vertical stress on the surface of the level unit at depth $z$ in zone I is obtained as:

$$
\sigma_{v 1}=\frac{\gamma}{B}-\frac{\gamma}{B} e^{\left(-\frac{B}{A} z\right)}
$$

When $z=H / 2-\Delta z / 2, \sigma_{\mathrm{v} 1}=D_{1}$ is regarded as the equivalent load on the top surface of zone II.

$$
D_{1}=\frac{\gamma}{B}-\frac{\gamma}{B} e^{-\frac{B}{A}\left(\frac{H}{2}-\frac{\Delta z}{2}\right)}
$$

Taking into account the overall static balance of the middle transition layer in zone II, we can get

$$
Q^{\prime} \sigma_{v 2}+S^{\prime} \sigma_{v 2}^{\prime}-T^{\prime}=0
$$

in which,

$$
\left.\begin{array}{l}
Q^{\prime}=k_{a w n 2} \tan \delta\left(\frac{\Delta z}{2}+h-\frac{H}{2}\right)+\left(k_{2} \tan \delta-1\right) n H \\
S^{\prime}=k_{a w n 2} \tan \delta\left(\frac{\Delta z}{2}+h-\frac{H}{2}\right)+\left(k_{2} \tan \delta+1\right) n H \\
T^{\prime}=\gamma n H\left(\frac{\Delta z}{2}+h-\frac{H}{2}\right)
\end{array}\right\}
$$

Taking $\sigma_{\mathrm{v} 2}=D_{1}$ at depth $z=H / 2-\Delta z / 2$ as the known loading conditions, $\sigma_{\mathrm{v} 2}^{\prime}$ at the bottom of the layer can be obtained. Assuming $\sigma_{\mathrm{v} 2}^{\prime}=D_{2}$, it can also be regarded as the equivalent load on the top surface of zone III.

Similarly, the distribution of the earth pressure $\sigma_{\mathrm{h} 2}$ along the height $\Delta z$ of the middle transition zone can be considered a linear distribution approximately.

$$
\sigma_{h 2}=k_{a w n 2}\left[D_{1}+\left(D_{1}-D_{2}\right) \frac{H / 2-\Delta z / 2-z}{(\Delta z / 2+h-H / 2)}\right]
$$

Considering the equivalent load on the top surface of zone III, the vertical stress on the surface of the level unit at depth $z$ is

$$
\sigma_{v 3}=\frac{\gamma}{G^{\prime}}+\left(D_{2}-\frac{\gamma}{G^{\prime}}\right) e^{\frac{G^{\prime}}{F^{(}(h-z)}}
$$

in which, 


$$
\left.\begin{array}{rl}
F^{\prime} & =1+k_{3} \tan \delta^{\prime} \\
G^{\prime} & =\frac{2 K_{a w n 3} \tan \delta^{\prime}}{n H}
\end{array}\right\}
$$

432

440

Then we can take $\sigma_{\mathrm{v} 3}=D_{3}$ at depth $z=H_{1}$ as the known loading conditions of equivalent load on the top surface of zone IV.

$$
D_{3}=\frac{\gamma}{G^{\prime}}+\left(D_{2}-\frac{\gamma}{G^{\prime}}\right) e^{\frac{G^{\prime}}{F^{\prime}\left(h-H_{1}\right)}}
$$

The vertical stress in zone IV is

$$
\sigma_{v 4}=\frac{-\gamma(H-z)}{J-L}+\left(D_{3}+\frac{\gamma H_{2}}{J-L}\right)\left(\frac{H-z}{H_{2}}\right)^{\frac{L}{J}}
$$

\section{Resultant force and height of action point}

When $\sigma_{\mathrm{h} 1}, \sigma_{\mathrm{h} 2}, \sigma_{\mathrm{h} 3}$, and $\sigma_{\mathrm{h} 4}$ are integrated along with the wall height, the horizontal component $E_{\mathrm{ax}}$ of resultant force for earth pressure on the whole retaining wall can be obtained.

$$
\begin{aligned}
& E_{a x}=\int_{0}^{H_{1}} \sigma_{h 1} d z+\int_{H_{1}}^{h} \sigma_{h 2} d z+\int_{h}^{(H / 2+\Delta z / 2} \sigma_{h 3} d z \int_{(H / 2+\Delta z / 2)}^{H} \sigma_{h 4} d z= \\
& \gamma K_{a w n 1}\left[\frac{H_{1}}{B}+\frac{A}{B^{2}}\left[e^{\left(-\frac{B}{A} H_{1}\right)}-1\right]\right]+\frac{\gamma K_{a w n} 2}{F-G}\left(\frac{h^{2}}{2}-H h-\frac{H_{1}^{2}}{2}+H H_{1}\right) \\
& +\frac{F K_{a w n 2}}{F+G}\left(D_{1}+\frac{\gamma H_{2}}{F-G}\right)\left[(h-H)\left(\frac{H-h}{H_{2}}\right)^{\frac{G}{F}}+H_{2}\right]+K_{a w n 3}\left(\frac{D_{2}+D_{3}}{2}\right)\left(\frac{H}{2}+\frac{\Delta z}{2}-h\right) \\
& +\frac{K_{a w n 4}(H-\Delta z)}{8(J+L)}\left[\gamma(H-\Delta z)+4 J D_{3}\right]
\end{aligned}
$$

The expression of resultant force is given by

$$
E_{a}=\frac{E_{a x}}{\cos \delta}
$$

The height $y$ of the point of application of the resultant force is as follows

$$
\begin{aligned}
y=\frac{\int_{0}^{H_{1}} \sigma_{h 1}(H-z) d z+\int_{H_{1}}^{h} \sigma_{h 2}(H-z) d z+\int_{h}^{(H / 2+\Delta z / 2)} \sigma_{h 3}(H-z) d z+\int_{(H / 2+\Delta z / 2)}^{H} \sigma_{h 4}(H-z) d z}{E_{a x}} \\
=\frac{1}{E_{a x}} \cdot\left[\begin{array}{l}
\frac{K_{a w n 1} \gamma}{B}\left(-\frac{H_{1}^{2}}{2}+H H_{1}-\frac{A H}{B}+\frac{A^{2}}{B^{2}}\right)+\frac{A}{B^{2}} K_{a w n 1} \gamma e^{\left(-\frac{B H_{1}}{A}\right)}\left(H_{2}-\frac{A}{B}\right) \\
+\frac{K_{a w n} \gamma}{3(F-G)}\left[(H-h)^{3}-H_{2}^{3}\right]-\frac{F K_{a w n 2}}{G+2 F}\left(D_{1}+\frac{\gamma H_{2}}{F-G}\right)\left[(h-H)^{2}\left(\frac{H-h}{H_{2}}\right)^{\frac{G}{F}}-H_{2}^{2}\right] \\
+\frac{K_{a w n 3}}{4}\left(D_{2}+D_{3}\right)\left(\frac{H}{2}+\frac{\Delta z}{2}-h\right)\left(\frac{3 H}{2}-h-\frac{\Delta z}{2}\right) \\
+\frac{K_{a w n 4}(H-\Delta z)^{2}\left[\gamma(H-\Delta z)+6 J D_{3}\right]}{24(L+2 J)}
\end{array}\right]
\end{aligned}
$$


In the first case, when $\Delta z / 2 \geqslant H / 2-H_{1}$, the depth of the top surface of the transition zone is $h=$ $H_{1}$, and the calculation height $\left[H_{1}, h\right]$ of zone II is zero. In the calculation formula of $E_{\text {ax }}$ and $y$, the calculation components in zone II are zero, and the original zone II is canceled. For the second case, when $\Delta z / 2 \geqslant H_{1}-H / 2$, the calculated height of zone III is zero, and zone III is actually canceled.

When the aspect ratio $n$ is large, the slip plane slides out from the soil's top surface. In this paper, $H_{1}=0, \sigma_{\mathrm{h} 1}$ in the zone I is always zero, and the calculation components of zone I in the calculation formula of $E_{\text {ax }}$ and $y$ are all zero. In fact, the original zone I has been canceled, and this problem has developed into the earth pressure problem of infinite soil.

\section{Model test}

As shown in Figure 10, the self-made model is used for the experimental study (Toufigh 2012; Toufigh et al. 2018 ). The movable baffle on the left side of the sandbox is polypropylene plate, the fixed baffle on the right side is steel plate, the front side baffle is tempered glass, and the backside baffle is frame steel plate, simulating the flexible retaining wall close to the outer wall of the basement. The real object of the test model device is shown in Figure 11.

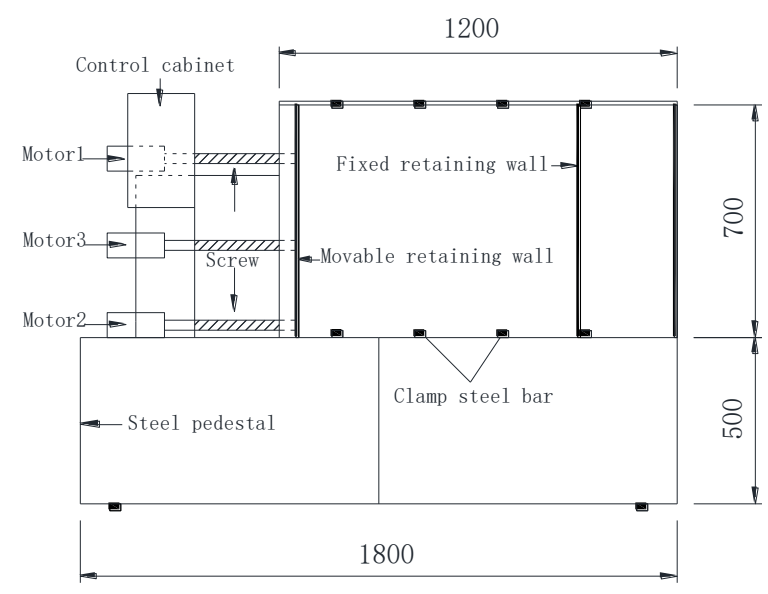

Fig.10 Construction detail of test box (unit: $\mathbf{m m}$ )

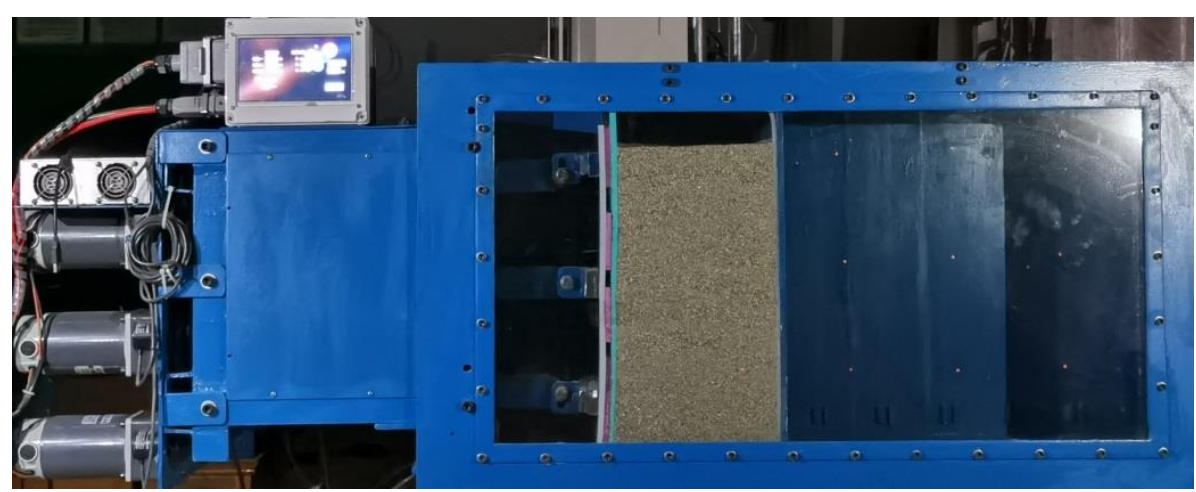




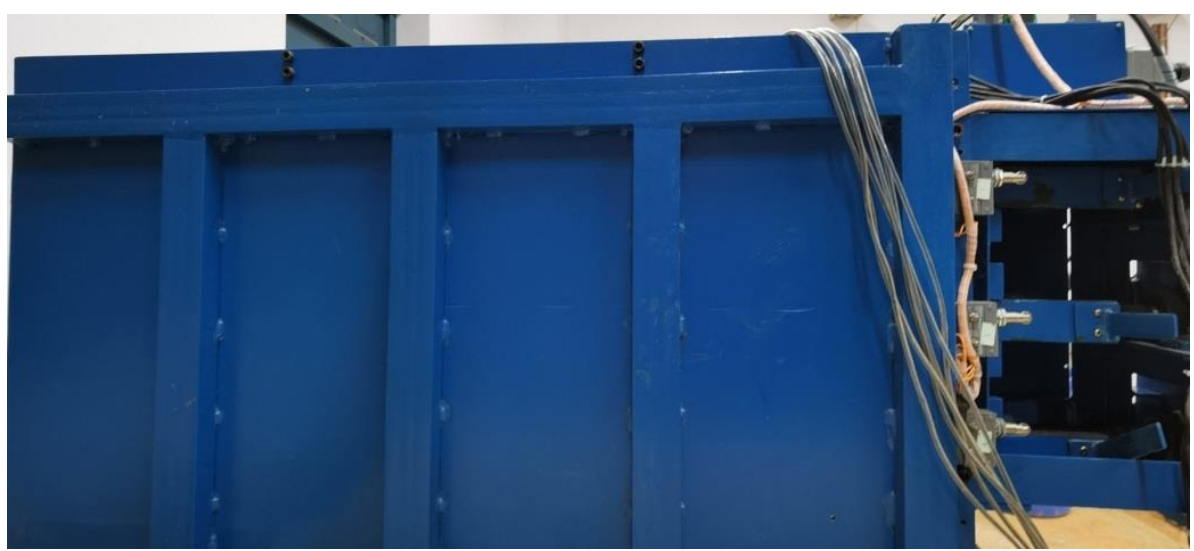

(b) Back view
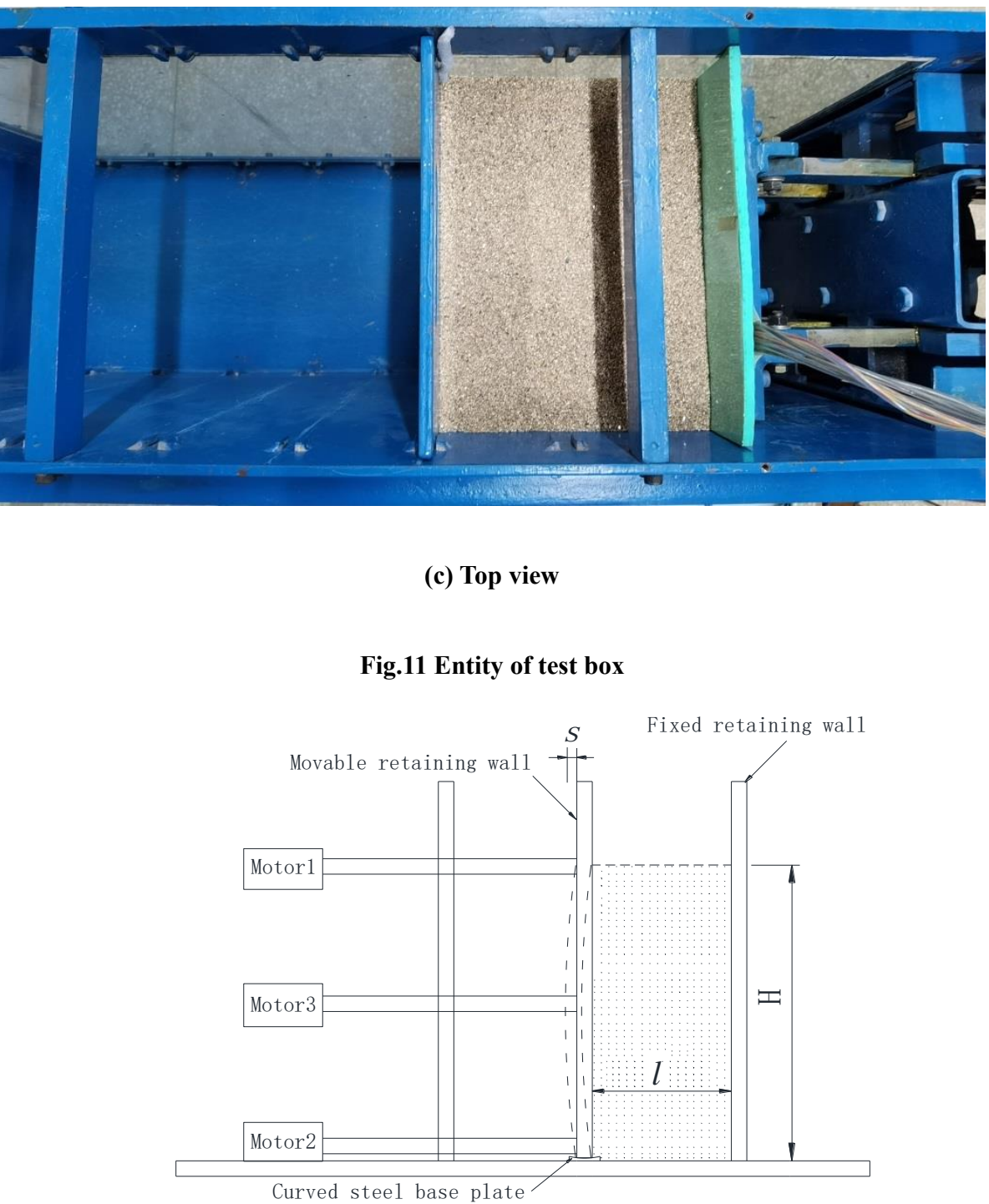

Three motors are installed on the outer side of the sand loading box, as shown in Figure 12. 
472 During the test, the upper and lower motors do not operate (simulating that the top of the retaining

473 wall is supported and the bottom of the retaining wall is embedded). When the middle motor is

474 running, the transmission shaft rotates slowly. The center of the movable baffle gradually moves

475 horizontally outward, forming a certain horizontal displacement and realizing the drum-shaped

476 deformation displacement mode.

477

478

479

480

481

482

483

484

485

486

487

488

489

490

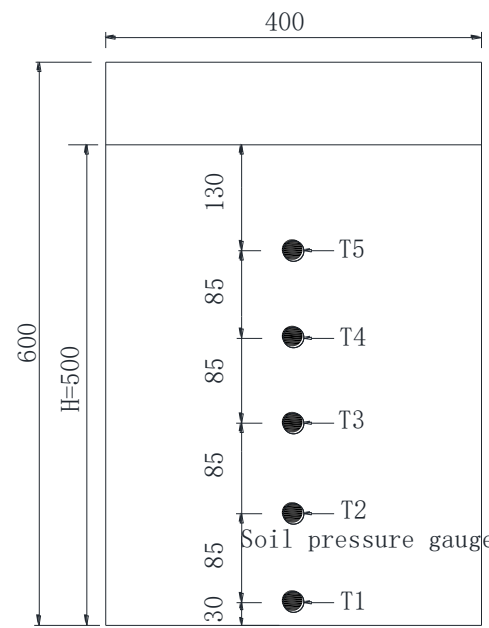

Fig.13 Layout of earth pressure cells (unit: $\mathrm{mm}$ )

The earth pressure is measured by five CYY9 micro earth pressure gauges arranged on the movable retaining wall, with a measuring range of $5 \mathrm{kPa}$ and a size of $\Phi 22 \mathrm{~mm} \times 13 \mathrm{~mm}$. The groove is excavated along the vertical centerline of the movable baffle at different depths, and the micro earth pressure gauges are embedded. The groove's depth is the same as the thickness of the gauges so as to reduce the influence of the gauges protruding from the baffle. Then, a hole is drilled at the groove side to lead out the wire of the earth pressure gauge from the back of the wall, as shown in Figure 13.

Four groups of soil pressure tests were carried out in this model test, and the specific test parameters are shown in Table 1 . The mechanical parameters of sand samples are cohesion $c=0$, internal friction angle $\varphi=36.5^{\circ}$, wall friction angle $\delta=24.3^{\circ}$, and unit weight of the tested sand specimen $\gamma=15 \mathrm{kN} / \mathrm{m}^{3}$.

Table 1 Parameters of tests

\begin{tabular}{cccc}
\hline Number & Height $/ \mathrm{m}$ & Width $/ \mathrm{m}$ & Ratio of width to height \\
\hline $1^{*}$ & 0.50 & 0.10 & 0.2 \\
$2^{*}$ & 0.50 & 0.15 & 0.3 \\
$3^{*}$ & 0.50 & 0.20 & 0.4 \\
$4^{*}$ & 0.50 & 0.25 & 0.5 \\
\hline
\end{tabular}




\section{Soil deformation analysis}

Taking the limited width as the PIV analysis area, image processing is carried out (Khosravi et al. 2013; Hu et al.2020b). The deformation displacement diagram of different width sand ( $n=$ $0.2,0.3,0.4,0.5,0.7)$ under the drum movement mode is gained, as shown in Figure 14.

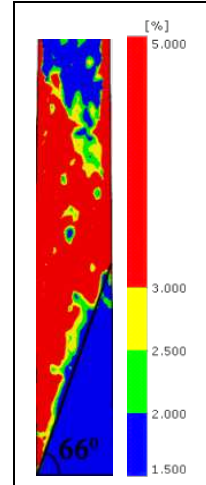

(a) $\mathrm{n}=0.2$

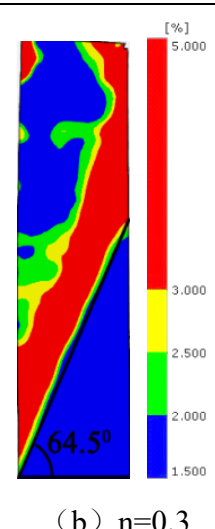

(b) $\mathrm{n}=0.3$

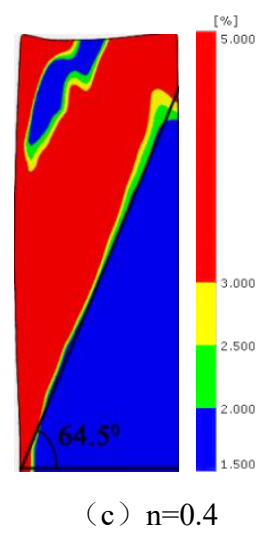

(c) $\mathrm{n}=0.4$

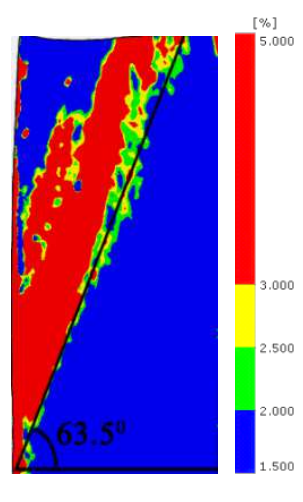

(d) $\mathrm{n}=0.5$

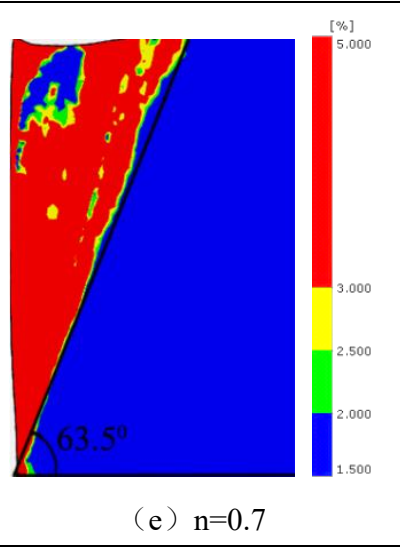

Fig.14 Displacement fields of soil for different $n$ (H=500mm)

As shown in Figure 14, the sliding failure surface is a plane developing upward from the bottom of the movable baffle. With the increase of the filled sand's width, the intersection of the slip plane and fixed baffle moves upward until the slip plane slides out from the filled sand's top surface. When the ratio of width to height increases from 0.4 to 0.5 , the intersection point of the slip plane gradually changes from fixed retaining wall to sand top surface. Therefore, it can be judged that the critical ratio of width height ratio of the finite soil in the model test is between 0.4 and 0.5 . When the sand width is greater than the critical width, the retaining soil is considered semi-infinite.

The ultimate fracture surface inclination angle is measured and compared with that calculated on the basis of the generalized Coulomb method, as shown in Table 2. It can be seen that the model test results are close to the theoretical calculation results in the limited width range. With the increase of aspect ratio, the ultimate fracture angle decreases gradually and becomes stable.

The experimental analysis shows that the fracture angle $\beta$ approaches to $\pi / 4+\varphi / 2=63.25^{\circ}$ under the infinite width (width height ratio $n=0.5,0.7$ ).

Table 2 Slip surface inclinations under different $n$

\begin{tabular}{cccc}
\hline & Ratio of width to height & Test result & Calculation result \\
& 0.2 & $/\left(^{\circ}\right)$ & $/\left(^{\circ}\right)$ \\
\hline $1^{\sharp}$ & 0.3 & $66.0^{\circ}$ & $64.22^{\circ}$ \\
$2^{\sharp}$ & 0.4 & $64.5^{\circ}$ & $63.20^{\circ}$ \\
$3^{\sharp}$ & $64.5^{\circ}$ & $62.07^{\circ}$
\end{tabular}




$\begin{array}{llll}4^{\sharp} & 0.5 & 63.5^{\circ} & 60.86^{\circ} \\ 5^{*} & & & \\ & 0.7 & 63.5^{\circ} & 60.08^{\circ}\end{array}$

511

\section{Earth pressure test results}

512

By using the theoretical method in this paper, the distribution of lateral active earth pressure

513 with different ratios $(n=0.1,0.2,0.3,0.4,0.5)$ in the model test is calculated, as shown in Figure
515

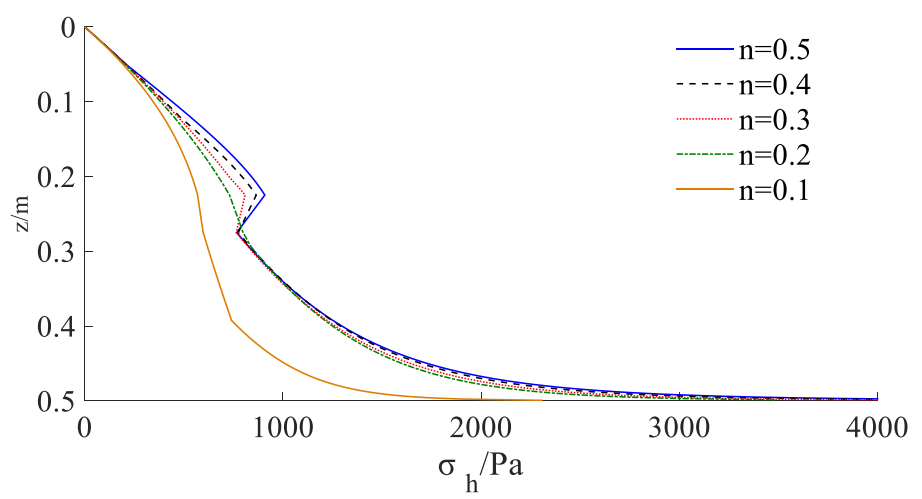

(a) $\mathrm{x}=0.1$

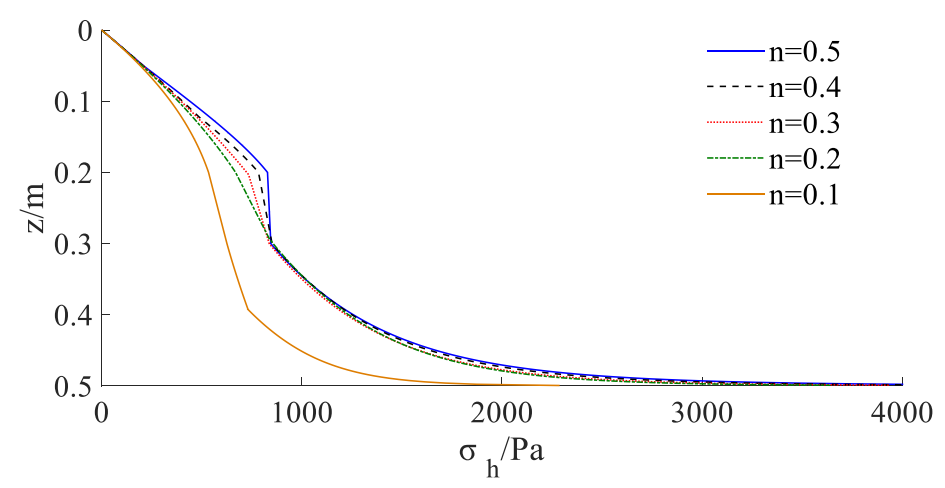

(b) $\mathrm{x}=0.2$

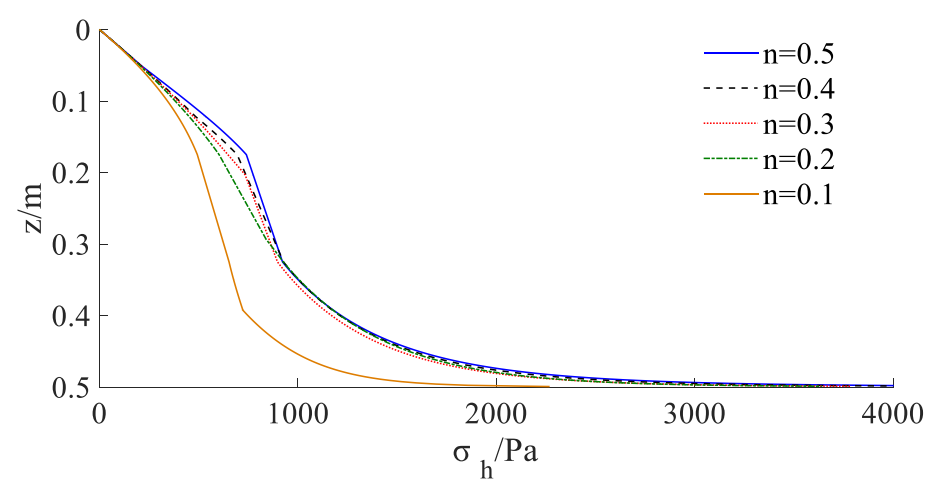

(c) $x=0.3$ 


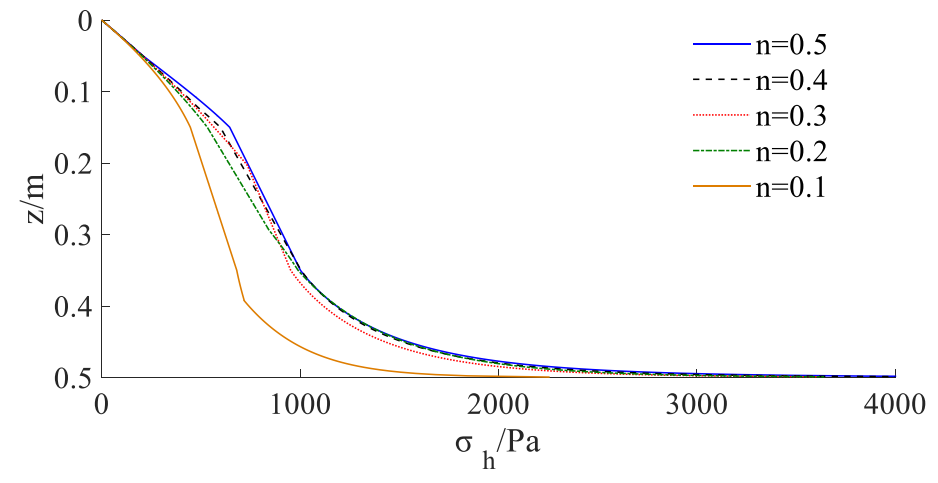

(d) $\mathrm{x}=0.4$

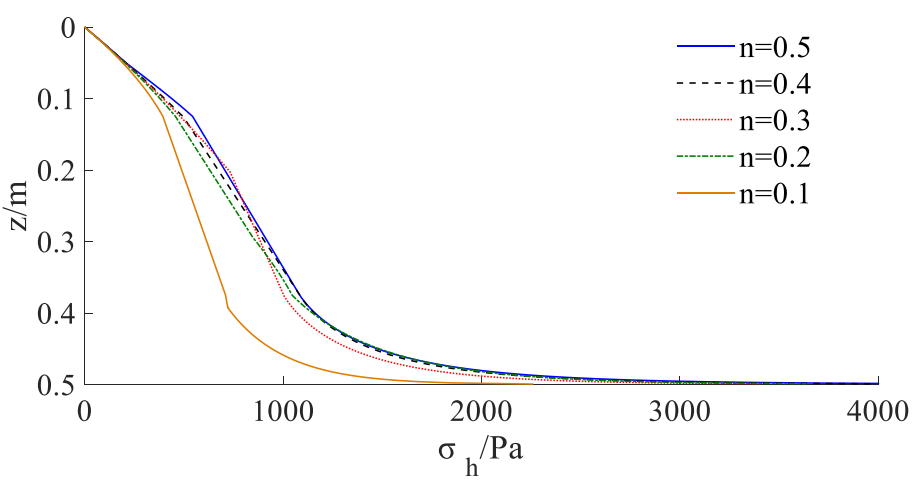

(e) $\mathrm{x}=0.5$

Fig.15 Theoretical calculation results under different $x$.

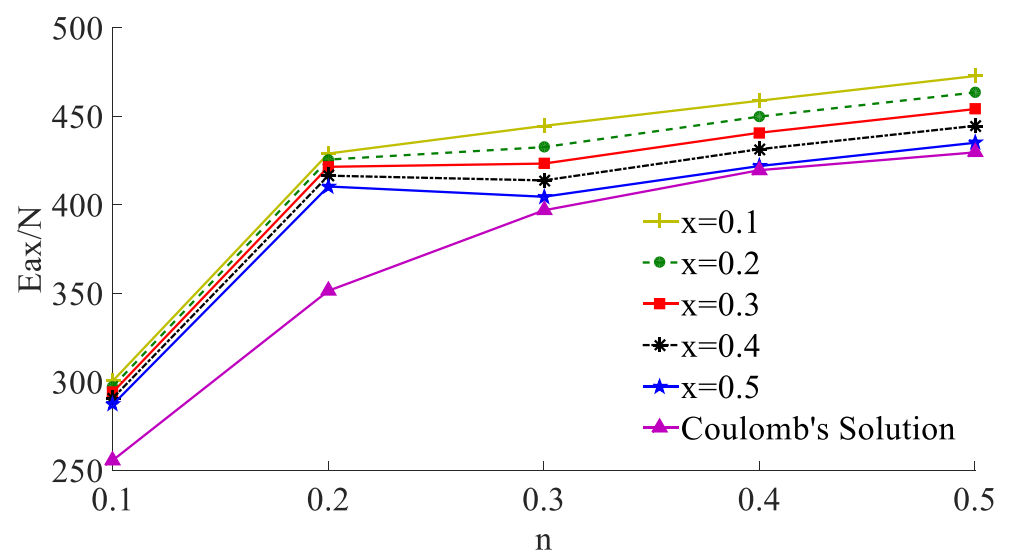

(a) Resultant force

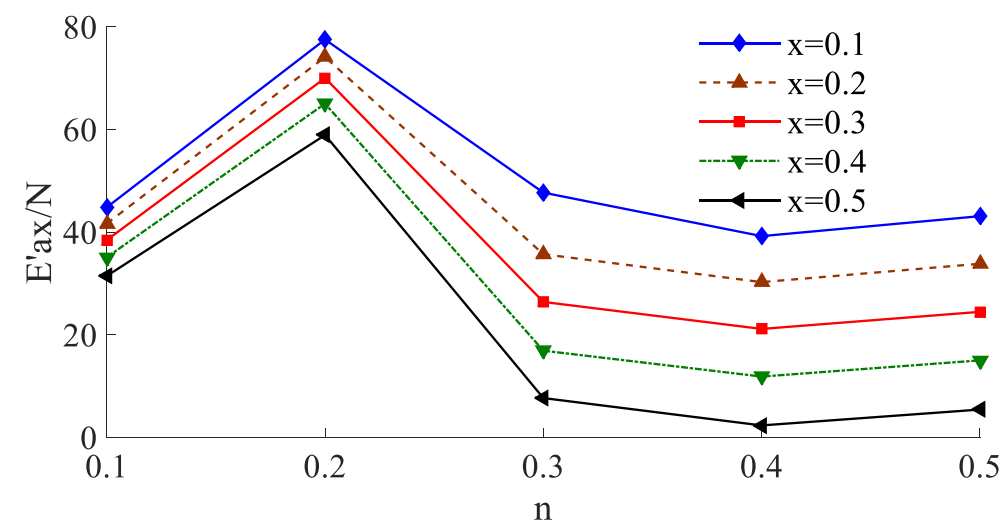


The theoretical calculation solution shows that the active earth pressure in the figure is nonlinear along with the height of the wall. The lateral earth pressure ruduces with the ruduce of ratio within the limited width. When the ratio decreases to $n=0.1$, the lateral earth pressure decreases significantly. As the limit state region ( $x$ from 0.1 to 0.5 ) increases, the lateral earth pressure near the retaining wall's top and bottom decreases gradually. In contrast, the lateral earth pressure in the middle of the retaining wall does not change significantly.

The resultant force increases with the increase of width to height and decreases with the rise of limit state area under the same ratio. When the width (reaching and exceeding the critical width) and the limit state region increase, the resultant thrust approach to that of Coulomb's result, which is consistent with the previous study, as shown in Figure 16(a). $E_{\text {ax }}^{\prime}$ is obtained by subtracting the prediction and Coulomb's solution. Figure 16(b) shows the difference at different $\mathrm{x}$.

Figure 17 shows the comparison of the theoretical calculation of lateral earth pressure distribution with the test results. It can be seen from the figure that the initial horizontal displacement of the retaining wall is smaller under the same ratio. The limit state region is small and only confined to the middle part of the wall. The lateral earth pressure on the upper and bottom of the wall is relatively large and highly nonlinear. With the increase of the drum deflection, most middle areas enter the active limit state, and the horizontal displacement increases while the earth pressure decreases. With the increase of the limit state region ( $x$ from 0.1 to 0.5 ), the horizontal lateral earth pressure distribution tends to be linearized gradually, and it is close to Coulomb's distribution of finite soil.

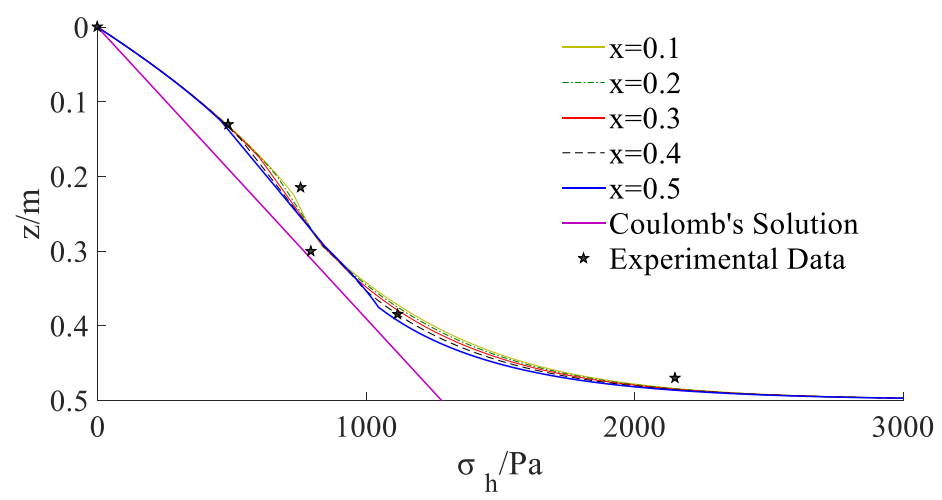

(a) $\mathbf{n}=0.2$ 


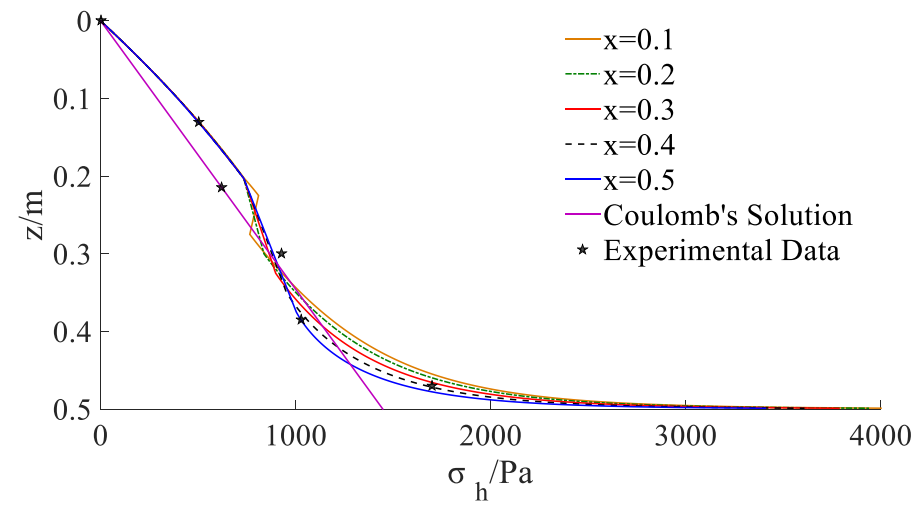

(b) $\mathbf{n}=\mathbf{0 . 3}$

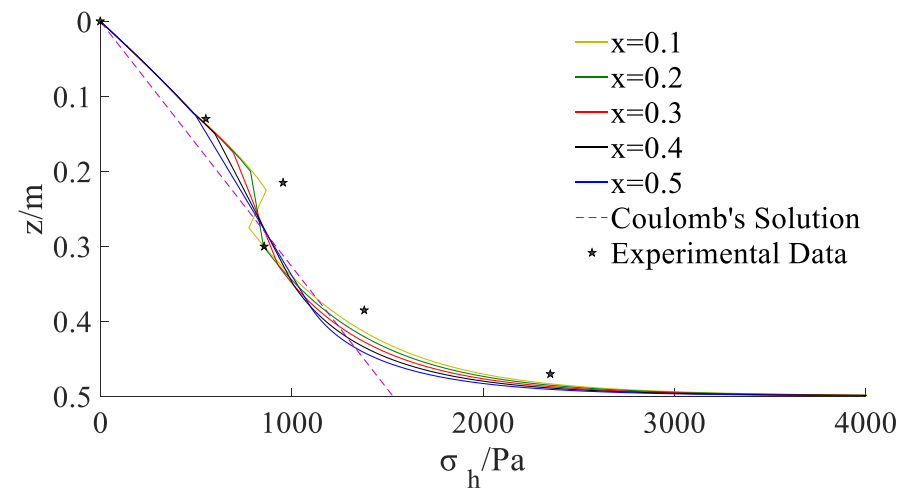

(c) $n=0.4$

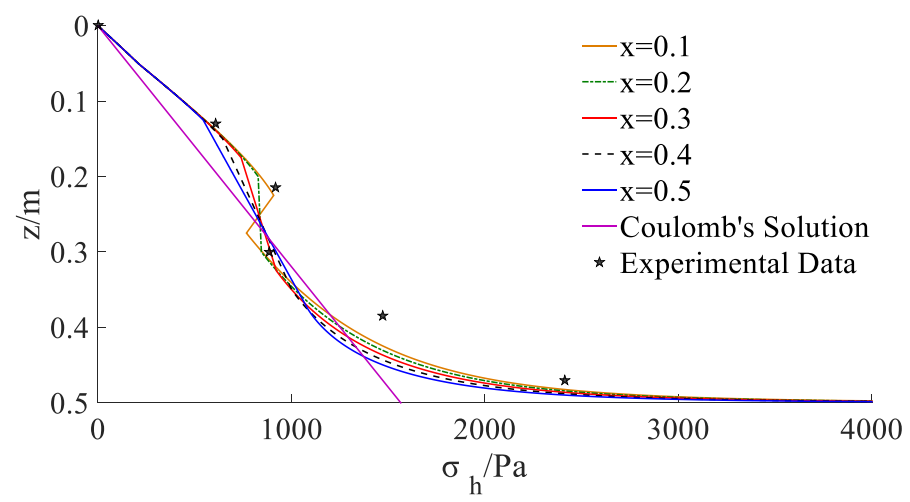

(d) $\mathbf{n}=\mathbf{0 . 5}$

Fig.17 Comparison of theoretical calculation with experimental results

The distribution of the earth pressure on the retaining wall calculated theoretically is consistent with that of the model test, and the distribution of the horizontal earth pressure in the middle area is concave. The drum deformation mode of retaining wall under different aspect ratio can be deemed that the upper part rotates about the top of the wall and the lower part rotates about the bottom of the wall. The supporting anchor structure restrains the upper part of the retaining wall, and the bottom is restrained by the fixed end, which makes the upper and bottom soil layers fail to reach the limit state completely. They are still in the active middle state, that is, the non-limit active state, and the shearing strength of the soil is insufficient. Therefore, the earth pressure distribution of the upper and the bottom measuring points on the retaining wall are greater than Coulomb's solution to the finite soil, while the middle area is completely in the active 

Coulomb's solution to the finite soil.

572

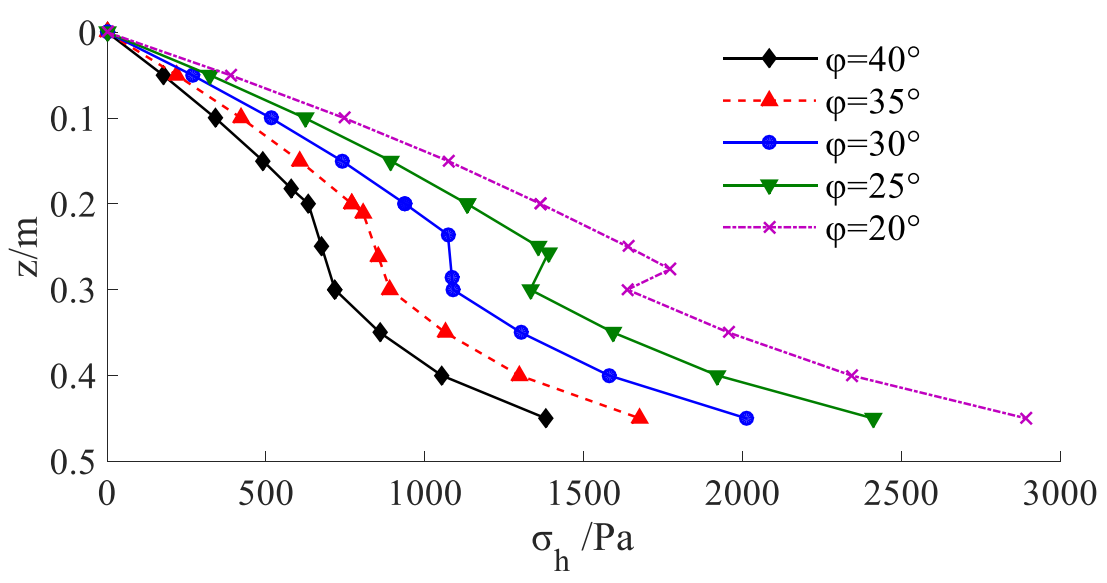

Fig.18 Active earth pressure distribution with different internal friction angle

The internal friction angle is an important factor affecting the active earth pressure. When $\mathrm{n}=$ 0.3 and $\mathrm{x}=0.2$, the active earth pressure decreases with the increase of internal friction angle, as shown in Figure 18. The active earth pressure without considering the soil arching is calculated and compared with the theoretical solution in this paper, as shown in Figure 19. When the soil arching is not considered, the active earth pressure acting on the upper part of the retaining wall is almost the same as considering the soil arching. However, the earth pressure acting on the middle and lower part of the retaining wall is obviously less than the earth pressure considering the soil arching. In particular, the earth pressure in the transition zone decreases obviously.

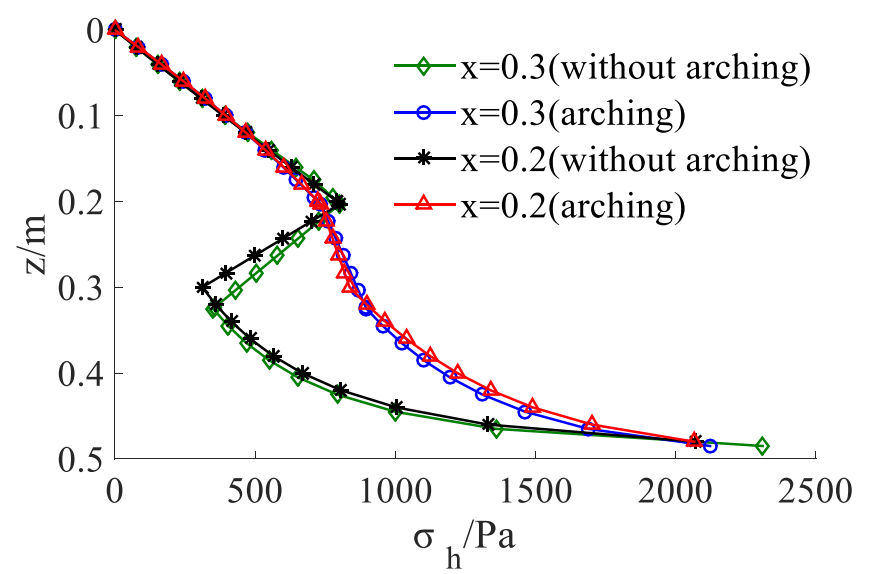

Fig.19 Theoretical calculation results with arching and without $\operatorname{arching}(\mathrm{n}=\mathbf{0 . 3})$

\section{Verification by comparison}

Taking Lu's model test (2003) as an example, dry sand is used in the test, $\gamma=16 \mathrm{kN} / \mathrm{m}^{3}, \varphi=31^{\circ}$, $\delta=2 \varphi / 3$, and the height of the flexible retaining wall with a single anchor is $2 \mathrm{~m}$. The displacement of the wall under each excavation condition is typical drum deformation. Using the theoretical method in this paper, the lateral earth pressure distribution is calculated for soils with infinite 
width (the ratio of width to height is taken as $n=0.5$ ). The distribution of earth pressure at different excavation depths obtained by this method, Ying's method (2014), and Lu's test (2003) is shown in Figure 20.

The calculated results of the proposed method are close to the calculated results of Ying (2014) and the measured values of the model test by $\mathrm{Lu}$ (2003), and the earth pressure distribution law is the same. The results show that the earth pressure on the middle part of the retaining wall decreases with the increase of the drum deformation and the horizontal displacement, even less than the Coulomb earth pressure strength. The earth pressure strength on the upper and lower part of the retaining wall is greater than Coulomb's solution owing to the effect of soils being in a non-limit state.

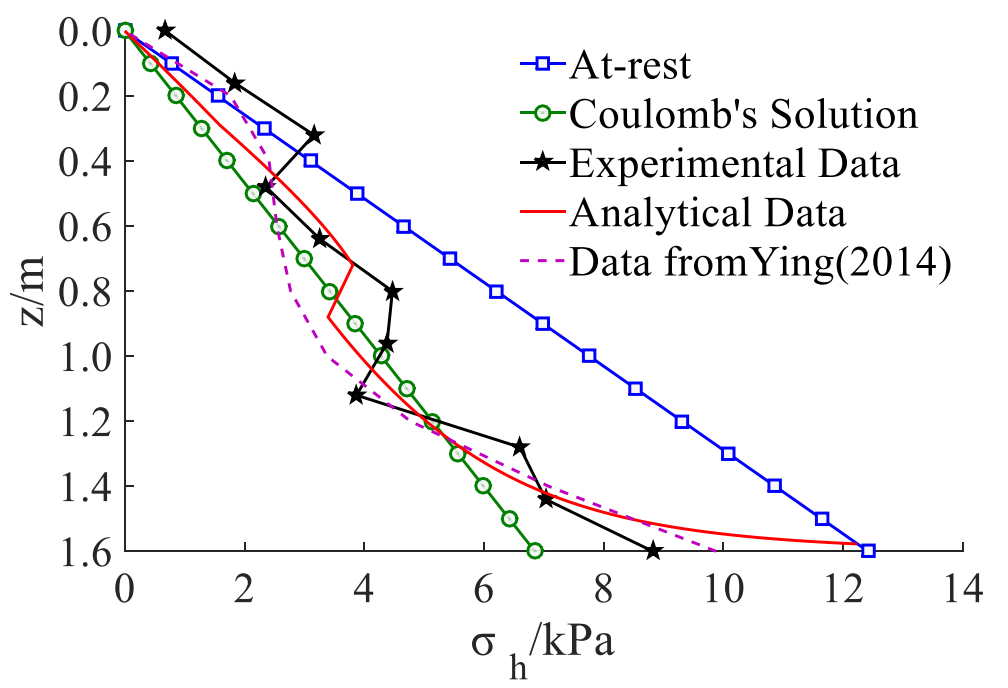

(a) Excavation depth of $30 \mathrm{~cm}$

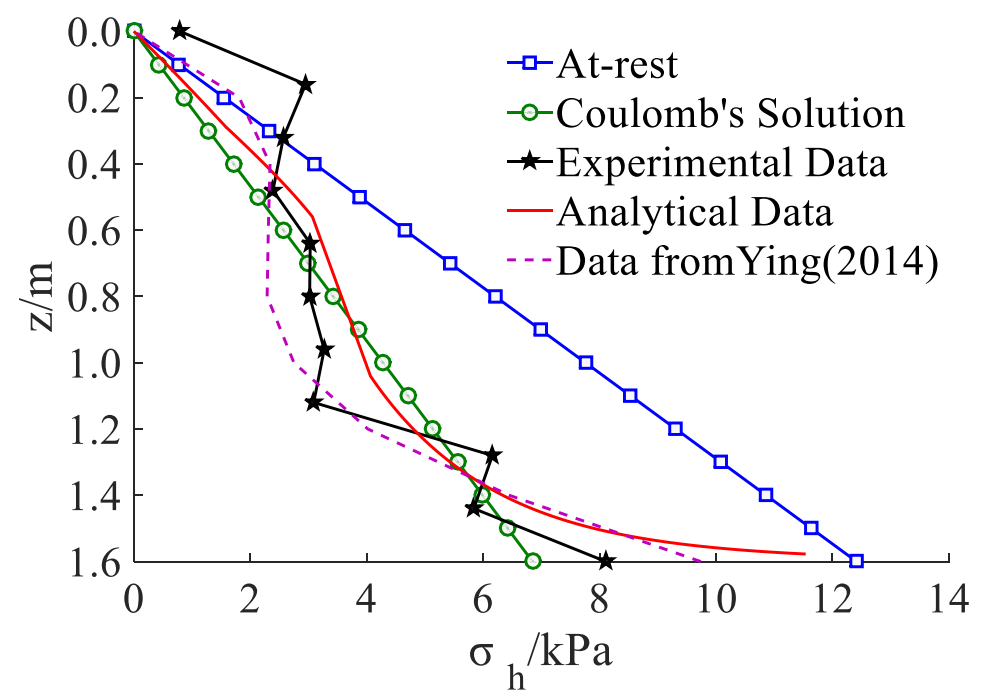

(b) Excavation depth of $60 \mathrm{~cm}$ 


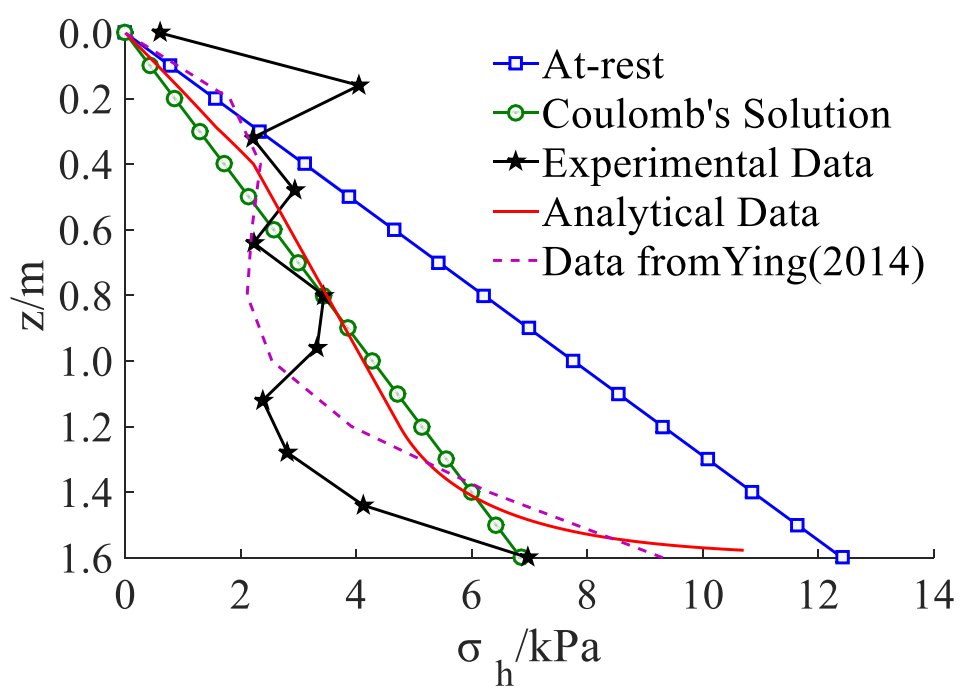

604

(c) Excavation depth of $90 \mathrm{~cm}$

Fig.20 Distributions of horizontal earth pressures

606

607

608

609

610

611

612

613

614

615

616

617

618

619

620

621

622

\section{Conclusion}

(1) Based on the characteristics of the drum deformation mode of the flexible retaining wall close to the outer wall of the basement, four zones are divided to establish the mechanical analysis model for the solution of the active earth pressure. The analysis model takes account of the relative movement trend of the fill with the limited width.

(2) The coefficient of active earth pressure is obtained using the soil arch theory and considering the horizontal shearing stress between differential layers. Considering the drum deformation of the retaining wall and the non-limit state of upper and lower soil layers, the linear relationship between the mobilization of internal friction angle and external friction angle and the magnitude of displacement is presented, and the differential layer analysis method is modified.

(3) The model tests are conducted, it is found that the failure angle reduces gradually and becomes stable with the increase of the ratio of width to height. When the ratio increases to infinite soil, the failure angle approaches $\pi / 4+\varphi / 2$.

(4)The test results show that the active earth pressure of soils with finite width is nonlinear, and the lateral earth pressure reduces with the reduction of the ratio of width to height in the critical width range. As the limit state region increases, the resultant force of earth pressure decreases under the same ratio of width to height.

(5)The earth pressure strength on the upper and bottom parts of the retaining wall is greater than the Coulomb solution for finite soil. The earth pressure strength on the middle part of the retaining wall decreases continuously, which is less than the Coulomb earth pressure strength. The 
concave in the middle of the distribution curve is close to a linear line, and the lower part of the distribution curve has higher nonlinearity.

Data Availability Statement: All data, models, and code generated or used during the study appear in the submitted article.

Author Contributions: H.W.D. contributed to the idea and funding support for the paper, H.W.D. and Z.X.N. carried out the analytical derivations and numerical examples, H.W.D., Z.X.N. and Z. Y.Q. carried out the model tests, L.X.H. and P.C.C. contributed to the supervision and revision.

Acknowledgments: The work is supported by Natural Science Foundation of Hunan Province, China (Grant No. 2017JJ2110), Key Scientific Program of Hunan Education Department, China (Grant No. 20A228) and The Program of Hunan Province Education Department, China (Grant No.19C0870)

Conflicts of Interest: The authors declare no conflict of interest.

\section{References}

Cao, W. G.(2019). "Calculation of passive earth pressure using the simplified principal stress trajectory method on rigid retaining walls." Computers and Geotechnics, https://doi.org/10.1016/j.compgeo.2019.01.021.

Chang, M. F. (1997). "Laterals earth pressure behind rotating walls." Canadian Geotechnical Journal, 34(2), 498-509.

Chen,F. Q., Lin,Y. J.,and Li,D. Y.(2019a).“Solution to active earth pressure of narrow cohesionless backfill against rigid retaining walls under translation mode." Soils and Foundations, 59(1), 151-161.

Chen, F.Q., Yang, J.T., and Lin, Y. J. (2019b). "Active earth pressure of narrow granular backfill against rigid retaining wall near rock face under translation mode." International Journal of Geomechanics, 19(12), 1943-5622.

Chen, L., Zhang, Y.X., and Ran, K.X. (2009). "Method for calculating active earth pressure considering shear stress." Rock and Soil Mechanics, 32(Supp.2), 219-223.

Clough, G.W., and O'Rourke T.D.(1990). "Construciton induced movements of institu walls." Specialty Conference on Design and Performance of Earth Retaining Structures, Atlantic, 439-470.

Fang, Y. S., and Ishibasbi, I. (1986). "Static earth pressures with various wall movements." Journal of Geotechnical Engineering, ASCE, 112(3), 317-333.

Gong, C., Yu, J. L., Xu, R. Q., and Wei, G. (2005). "Calculation of earth pressure against rigid retaining wall rotating outward about base." Journal of Zhejian University, 39(11), 1690-1694.

Handy, R. L. (1985). “The arch in soil arching." Journal of Geotechnical Engineering, 111(3), 302-318.

Hu, W.D., Liu, K.X., Zhu, X.N., et al. (2020a). “Active Earth Pressure against Cantilever Retaining Wall adjacent 
to Existing Basement exterior Wall." International Journal of Geomechanics. https://doi. org/10.1061/(ASCE)GM.1943-5622.0001853

Hu, W.D., Liu, K.X., Zhu, X.N., et al. (2020b). “Active earth pressure against rigid retaining walls for finite soils in sloping condition considering shear stress and soil arching effect." Advances in Civil Engineering, https://doi. org/10.115/2020/6791301.

Hu, W.D., Zhu, X.N., and Zhou, X.Y. (2019). "Experimental study on passive earth pressures of cohesionless soils with limited width against cantilever piles flexible retaining walls." Chinese Journal of Rock Mechanics and Engineering, 38(supp.2), 3748-3757.

Jie, Y. X. (2019). “Analyses on finite earth pressure and slope safely factors.” Journal of Tsinghua University (Science and Technology), 59(8), 619-627.

Khosravi, M. H., Pipatpongsa, T., and Takemura,J. (2013). "Experimental analysis of earth pressure against rigid retaining walls under translation mode." Geotechnique, 63(12), 1020-1028.

Lin,Y.J., Chen,F.Q., Yang,J.T.et al.(2000). “Active earth pressure of narrow cohesionless backfill on inclined rigid retaining walls rotating about the bottom." International Journal of Geomechanics,20(7), https://doi. org/10.1061/(asce)gm.1943-5622.0001727.

Liu, Z. Y. (2018). “Active earth pressure calculation of rigid retaining walls with limited granular backfill space.” China Journal of Highway Transport, 31(2), 154-164.

Liu, Z.Y., Chen, J., Li, D.Y. (2016). “Calculation of active earth pressure against rigid retaining wall considering shear stress." Rock and Soil Mechanics, 37(9), 2443-2450.

Lu, P.Y., Yan, C., and Gu, X.L.( 2003). "Sand model test on the distribution of earth pressure.” China Civil Engineering Journal, 36(10),84-88.

Matsuzaw, A. H. (1996). “Analyses of active earth pressure against rigid retaining walls subjected to different modes of movement." Soils and Foundations, 36(3), 51-65.

Mei, G.X., Zai, J.M., and Xu,J.(2001). "Earth pressure computing method lacement and time effect." Chinese Journal of Rock Mechanics and Engineering, 20(S1),1079-1082.

Milligan ,G,W,E. (1983). “Soil deformations near anchored sheet-pile walls. ” Geotechnique, 33(1),41-55.

Naikai, T. (1985). "Finite element computations for active and passive earth pressure problems of retaining wall." Soils and Foundations,25(3), 98-112.

Paik, K. H., Salgado, R. (2003). "Estimation of active earth pressure against rigid retaining walls considering arching effects." Geotechnique, 53(7), 643-653.

Take, W. A., and Valsangkar, A. J. (2001). "Earth pressures on unyielding retaining walls of narrow backfill width." Journal of Canadian Geotechnical, 38, 1220-1230.

Toufigh, V. (2012). "Experimental and Analytical Studies of Geo-Composite Applications in Soil Reinforcement." Dissertation, University of Arizona, Tucson.

Toufigh, V. and Pahlavani, H. (2018). "Probabilistic-Based Analysis of MSE Walls Using the Latin Hypercube Sampling Method.” International Journal of Geomechanics, 18(9), 04018109. 
Wang, Y. Z., Li, W., and Huang, C. H. (2003). "Distribution of active earth pressure with wall movement of rotation about base." Chinese Journal of Geotechnical Engineering, 25(2), 208-211.

698 Wang, H. L., Song, E. X., and Song, F. Y. (2014a). "Calculation of active earth pressure for limited soil between existing building and excavation." Engineering Mechanics, 31(4), 76-81.

Wang, J., Xia, T.D., and He, P.F. et al, (2014b). “Analysis of active earth pressure on rigid retaining walls considering soil arching." Rock and Soil Mechanics, 35(7), 1914-1920.

Xie, M.X., Zhen J. J., and Cao, W.Z. (2019). "Study of active earth pressure against embankment retaining wall of limited backfill." Journal of Huazhong University of Science and Technology (Natural Science Edition) ,47(2), $1-6$.

Ying, H.W., Zhu W., Zheng, B.B., et al.(2014). "Calculation and distribution of active earth pressure against flexible retaining walls. ” Chinese Journal of Geotechnical Engineering, (11),1-6.

Ying, H.W., Cai, Q.P, Huang, D., et al.(2008). "Numerical analysis on active earth pressure against flexible retaining wall. " Chinese Journal of Geotechnical Engineering, (10),12-15.

Xu, R.Q.(2000). "Methods of earth pressure calculation for excavation." Journal of Zhejiang University, $34(4), 370-375$.

Zhu, J.M., and Zhao, Q. (2014). "Unified solution to active earth pressure and passive earth pressure on retaining wall considering soil arching effects.” Rock and Soil Mechanics, 35(9), 2501-2505. 